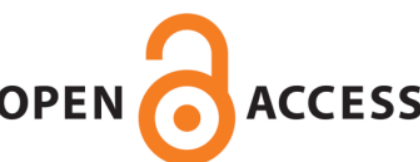

OPEN ACCESS

UWS Academic Portal

\title{
Online Risk-based Supervisory Maneuvering Guidance for Small Unmanned Aircraft Systems
}

Fang, Scott Xian; Rolland, Luc; O'Young, Siu

Published in:

Journal of Guidance, Control, and Dynamics

DOI:

10.2514/1.G003526

Published: 20/09/2018

Document Version

Peer reviewed version

Link to publication on the UWS Academic Portal

Citation for published version (APA):

Fang, S. X., Rolland, L., \& O'Young, S. (2018). Online Risk-based Supervisory Maneuvering Guidance for Small Unmanned Aircraft Systems. Journal of Guidance, Control, and Dynamics, 41(12).

https://doi.org/10.2514/1.G003526

\section{General rights}

Copyright and moral rights for the publications made accessible in the UWS Academic Portal are retained by the authors and/or other copyright owners and it is a condition of accessing publications that users recognise and abide by the legal requirements associated with these rights.

Take down policy

If you believe that this document breaches copyright please contact pure@uws.ac.uk providing details, and we will remove access to the work immediately and investigate your claim. 


\title{
Online Risk-based Supervisory Maneuvering Guidance for Small UAS Detect-and-Avoid Systems
}

\author{
Scott Xiang Fang* and Siu O'Young ${ }^{\dagger}$ \\ Faculty of Engineering and Applied Science, Memorial University, St. John's, NL, AlB 3X5, Canada \\ Luc Rolland \\ School of Engineering and Computing, University of West Scotland, Paisley, Scotland, PA1 2BE, UK
}

To achieve a level of safety equivalent to manned aircraft in the national airspace system, the pilot-in-command of small unmanned aircraft systems should be able to maintain situational awareness and make necessary maneuvers to avoid potential conflicts with nearby air traffic during mid-air encounters. However, due to ever-changing flight environments, the pilotin-command often mis-estimates collision risks and cannot engage appropriate maneuvers to prevent mid-air traffic from violating the safety boundaries of small unmanned aircraft systems. To fix this problem, an online risk-based supervisory maneuvering guidance method is therefore designed and developed in this paper to quantitatively assess mid-air collision risks and provide online mitigation solutions for detect-and-avoid systems to help the pilot-in-command identify hazards and trigger avoidance maneuvers before a safety boundary violation occurs.

\section{Nomenclature}

$\beta=$ detected traffic aircraft bearing angle

$d_{x}=$ traffic aircraft relative position on the $x$ axis (latitude)

$d_{y}=$ traffic aircraft relative position on the $y$ axis (longitude)

$d_{h}=\quad$ traffic aircraft relative position on the $h$ axis (altitude)

$H M D=$ horizontal separation

$\psi \quad=$ aircraft heading

$\dot{\psi} \quad=$ aircraft turn rate

$P_{\text {risk }}(X)=$ risk level of event $X$ occurring

$r \quad=$ horizontal range

$\tau_{\text {mod }}=$ modified range tau

$t_{\mathrm{cPA}}=$ time to the horizontal closest point of approach

\footnotetext{
*PhD Candidate, Faculty of Engineering and Applied Science, Memorial University, St. John's, NL, A1B 3X5, Canada.

†Professor, Faculty of Engineering and Applied Science, Memorial University, St. John's, NL, A1B 3X5, Canada.

${ }^{\ddagger}$ Lecturer, School of Engineering and Computing, University of West Scotland, Paisley, Scotland, PA1 2BE, UK.
} 


$\begin{array}{ll}v & =\text { horizontal velocity on the } x-y \text { plane } \\ v_{r x} & =\text { horizontal relative velocity on the } x \text { axis (latitude) } \\ v_{r y} & =\text { horizontal relative velocity on the } y \text { axis (longitude) } \\ v_{r h} & =\text { vertical relative velocity on the } h \text { axis (altitude) } \\ V_{s} & =\text { alert zone } \\ \text { Subscripts } & \\ \text { AZ } & \text { collision avoidance } \\ \text { CA } & =\text { near mid-air collision } \\ \text { NMAC } & \text { self-separation } \\ \text { SS } & =\text { traffic aircraft } \\ \text { TRAFFIC } & \text { unmanned aircraft } \\ \text { UA } & \text { well clear } \\ \text { WC } & \end{array}$

\section{Introduction}

$\mathrm{T}$ HE ability to Detect and Avoid (DAA) other aircraft during flight operations is an essential part of regulations governing the general operation of aircraft in the National Airspace System (NAS). Small Unmanned Aircraft Systems (UAS), due to their limitations of Size, Weight, and Power (SWaP), cannot have installed the same DAA systems as manned General Aviation (GA) aircraft, such as the airborne radar, the Traffic Collision Avoidance System (TCAS), and the Automatic Dependent Surveillance-Broadcast (ADS-B), to achieve a level of safety equivalent to manned GA aircraft [1]. At the same time, small UAS aerodynamic characteristics are very different from manned aircraft, so that the collision avoidance solutions for manned aircraft are not always suitable for small UAS during flight operations. To reflect this reality, a small UAS DAA system, based on light-weight airborne ADS-B and ground portable radar systems, is proposed by the RAVEN project to assist small UAS in achieving the equivalent level of safety as manned GA aircraft, for the future approval of integrating small UAS into the NAS. As shown in Fig. 1, the Detect System of the proposed DAA system is developed to detect and track cooperative and non-cooperative mid-air traffic nearby small UAS operating areas, and the Avoid System of the proposed DAA system is designed to quantitatively carry out risk analysis and decision-making to help the Pilot-In-Command (PIC) improve situational awareness and steer small UAS to safe regions (when required) during mid-air encounters [2].

The research described in this paper is focused on the mitigation solution module (the third module in the Avoid System for the proposed DAA system), which is designed to provide small UAS DAA mitigation guidance to help the

*The RAVEN project is based at Memorial University, St. John's, NL, Canada, and their main research objective is to develop intelligent DAA systems to allow small UAS to share the same airspace with manned aviation. 


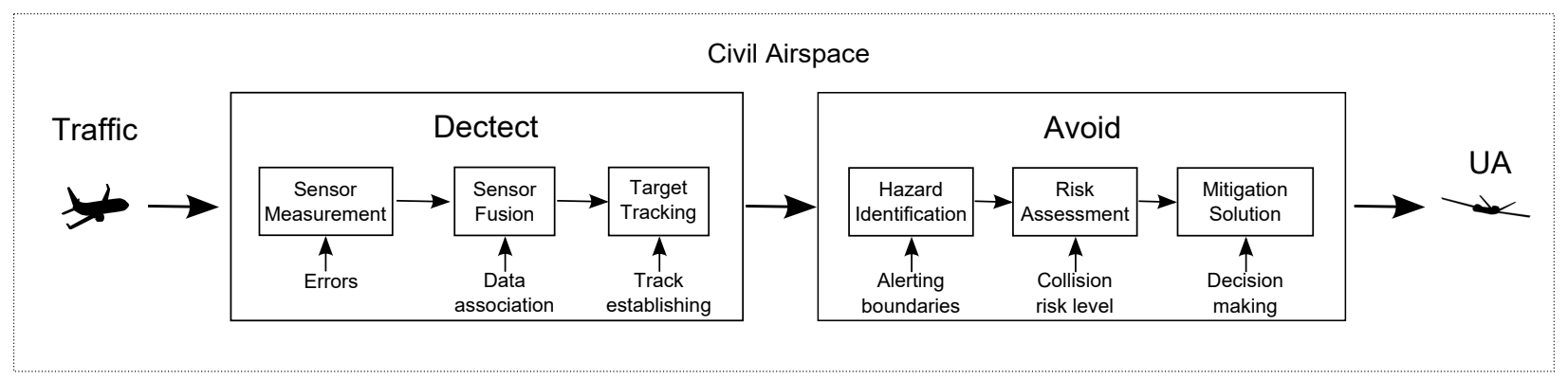

Fig. 1 Block diagram for the proposed DAA system.

PIC make final decisions on whether maneuvers are required to avoid potential conflicts in mid-air encounters. In the mitigation solution module, small UAS DAA mitigation guidance is usually provided to answer three core concerns: when to maneuver, how to maneuver, and how long for maneuvers, all of which are related to maneuvering timing and choices such as the turning direction, the turn rate, and the duration. A number of guidance methods have been reviewed and summarized for solving such questions in [3, 4]. For instance, a predefined guidance method is designed based on predefined rules to determine escape trajectories. This is efficient in specific encounters, but in most cases, it is less effective and less optimal than an optimized guidance method [5]. As for the system response time, the predefined guidance method can provide an avoidance maneuvering solution immediately [4, 5]. The optimized guidance method, on the other hand, usually requires extra computation time to search for the best solutions from all possible maneuvering options in mid-air encounters [6]. To overcome this drawback for real-time decision making, the TCAS selects the least-aggressive vertical maneuver within a limited set of potential climb or descent maneuvers that can provide adequate separation between aircraft during mid-air encounters [3, 7]. However, this TCAS strategy cannot be directly adopted for new DAA guidance system $\{$ since preferred horizontal maneuvers have many more maneuvering options (e.g., various turn rates and heading changes) than vertical maneuvers. For solving this challenge, a novel learning-based decision tree method is therefore proposed and designed in this paper to provide real-time DAA guidance without demanding extra computation time to search for the best solutions from all possible maneuvering options.

This method is inspired by a Google artificial intelligence (AI) program, AlphaGo, which has recently mastered the complex ancient Chinese board game, "Go", defeating the best human "Go" game players in the last two years [9, 10]. AlphaGo is not directly programmed to play "Go" games; instead, it is designed to learn how to play the game by a general purpose algorithm through analyzing millions of human expert-played "Go" games (supervised learning) and AlphaGo self-played "Go" games (reinforcement learning)[9]. By training through supervised learning and reinforcement learning, two knowledge-based statistical networks: the policy network (how to play the game in the next run) and the value network (how to evaluate the probability of winning the game with the current decision),

\footnotetext{
${ }^{\dagger}$ Note that the TCAS has been designed to avoid potential mid-air collisions by vertical maneuvers. In case of miscommunication with existing TCAS-equipped aircraft, new DAA systems that are capable of horizontal maneuvers must expect to adapt themselves when necessary [8].
} 
are thus constructed to reduce the breadth and the depth of the MC searching tree to locate the best solutions in "Go" games [10]. It is true that AlphaGo is designed based on the optimization method and requires extra computation power over thousands of computers to play games. However, more importantly, its design strategy (two knowledge-based statistical networks: the policy network and the value network) as well as the strategy used by TCAS (a limited set of potential maneuvers) can be adopted in this paper to establish the learning-based decision tree method to provide real-time supervisory DAA guidance for small UAS. An outline of the paper is as follows. In Section II the formal definitions of safety and alerting boundaries for mid-air encounters are given along with the related DAA parameters and terminologies. In Section III, the learning-based DAA guidance method is designed and developed for small UAS DAA systems. In Section IV the mitigation performance of the new-developed DAA guidance method is analyzed and discussed. Finally, conclusions and future work are presented in Section $\mathrm{V}$

\section{DAA Parameters and Terminologies}

To explain the DAA supervisory guidance methodologies designed in this paper, it is necessary to identify the basic DAA parameters and terminologies that are related to, and will be used in, the research.

\section{A. DAA Parameters}

As shown in Fig. 2. for convenience of analysis and implementation, air traffic positions in mid-air encounters are defined on the local three-dimensional Cartesian coordinates $(x, y, h)$ with respect to the Unmanned Aircraft (UA), on which the $x$ axis is pointing to the north for latitude, the $y$ axis is pointing to the east for longitude, and the $h$ axis is pointing up for altitude. In addition, $\psi$ is the traffic heading relative to the north, and $v$ is the horizontal velocity of the traffic in a given three-dimensional space.

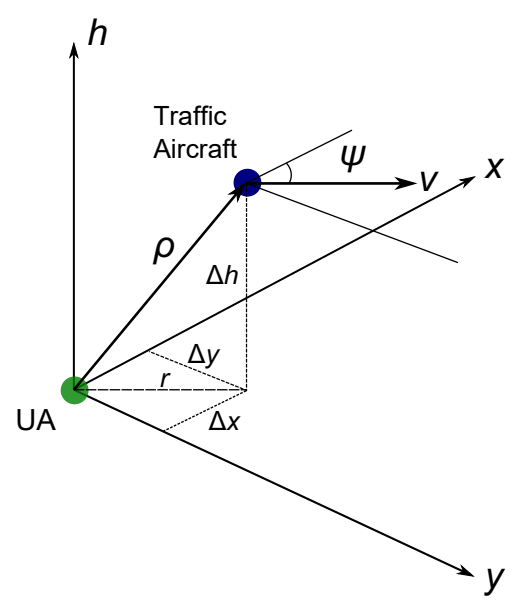

Fig. 2 Aircraft positions in a given three-dimensional space [11]. 
In Fig. 2. $(\Delta x, \Delta y, \Delta h)$ are local positions for the traffic relative to the UA. Assume that

$$
\begin{aligned}
& d_{x}=\Delta x=x_{\text {тRAFFC }}-x_{\mathrm{UA}} \\
& d_{y}=\Delta y=y_{\text {TRAFFC }}-y_{\mathrm{UA}} \\
& d_{h}=\Delta h=h_{\text {TRA } A \mathrm{AC}}-h_{\mathrm{UA}}
\end{aligned}
$$

The traffic velocities relative to the UA in the three-dimensional space are

$$
\begin{gathered}
v_{r x}=v_{\text {TRAFFC }} \cos \left(\psi_{\text {TRAFFC }}\right)-v_{\mathrm{UA}} \cos \left(\psi_{\mathrm{UA}}\right) \\
v_{r y}=v_{\text {TRAFHC }} \sin \left(\psi_{\mathrm{TRAFFIC}}\right)-v_{\mathrm{UA}} \sin \left(\psi_{\mathrm{UA}}\right) \\
v_{r h}=\dot{h}_{\text {TRAFTC }}-\dot{h}_{\mathrm{VAA}}
\end{gathered}
$$

Similarly, the horizontal range $r$ is

$$
r=\sqrt{d_{x}^{2}+d_{y}^{2}}
$$

The horizontal range rate $\dot{r}$ is

$$
\dot{r}=\frac{\mathrm{d} r}{\mathrm{~d} t}=\frac{d_{x} v_{r x}+d_{y} v_{r y}}{r}
$$

It is noted that the safe horizontal range to separate UA from other traffic often changes in mid-air encounters, in terms of various relative velocities between UA and traffic. Thus, to unify a safe separation threshold in risk assessment, a time-based range tau $(\tau)$ is introduced to evaluate the risk severity of potential collisions as [12]

$$
\tau=-\frac{r}{\dot{r}}(\text { if } \dot{r} \neq 0)
$$

Usually, a larger $\tau$ indicates lower collision risks and a smaller $\tau$ means higher collision risks. However, in the case of two tail-chase aircraft operated at similar velocities (i.e., range rate $\dot{r} \rightarrow 0$ ), the calculated $\tau$ from Eq. 9 will stay high even when the intruder is in a short horizontal range (e.g., $r<500 \mathrm{ft}$ ). In addition, this $\tau$ will not be able to provide sufficient alerting time to avoid a potential collision when a traffic suddenly accelerates. Thus, another modified range tau $\left(\tau_{\text {mod }}\right)$ is used to provide a minimum range, Distance MODification (DMOD) at which to alert regardless of the calculated $\tau$. This $\tau_{\text {mod }}$ is defined as [12, 13]

$$
\tau_{\text {mod }}=-\frac{r-\left(D M O D^{2} / r\right)}{\dot{r}}=-\frac{r^{2}-D M O D^{2}}{r \dot{r}}(\text { if } r \dot{r} \neq 0)
$$

\footnotetext{
†DMOD: an absolute distance threshold to alert the collision risk in mid-air encounters, e.g., DMOD $=4000 \mathrm{ft}$ to alert the loss of well clear.
} 
where $\mathrm{DMOD}=4000 \mathrm{ft}$ for the minimum of safety boundaries, and $\left(\mathrm{DMOD}^{2} / r\right)$ is a range buffer depending on the ratio of the DMOD and the horizontal range, i.e., $\left(\mathrm{DMOD}^{2} / r\right)=\mathrm{DMOD} \times\left(\frac{\mathrm{DMOD}}{r}\right)$.

Another important encounter parameter is the Horizontal Miss Distance (HMD) between the UA and other traffic in an encounter, which refers to the horizontal distance at the horizontal Closest Point of Approach (CPA) between two aircraft throughout the entire encounter [8, 14]. In general, the horizontal range of two aircraft is defined as the time-domain function

$$
r(t)=\sqrt{\left(x_{0}+v_{r x} t\right)^{2}+\left(y_{0}+v_{r y} t\right)^{2}}
$$

where $x_{0}$ and $y_{0}$ are the initial positions of the other traffic relative to the UA.

The minimal distance occurs when $\frac{\mathrm{d}\left(r(t)^{2}\right)}{\mathrm{d} t}=0$, so the time to CPA can be obtained by

$$
t_{\mathrm{cPA}}=\max \left(0,-\frac{x_{0} v_{r x}+y_{0} v_{r y}}{v_{r x}{ }^{2}+v_{r y}{ }^{2}}\right)
$$

where a positive $t_{\mathrm{cPA}}$ expresses closing geometries and zero indicates other non-closing geometries.

According to Eq. 11 and Eq. 12, the HMD of two aircraft in an encounter can be predicted from its current positions as [8]

$$
H M D=\sqrt{\left(d_{x}+v_{r x} t_{\mathrm{CPA}}\right)^{2}+\left(d_{y}+v_{r y} t_{\mathrm{CPA}}\right)^{2}}
$$

Similarly, the Vertical Miss Distance (VMD) between the UA and other traffic at the horizontal CPA can be predicted by

$$
V M D=d_{h}+v_{r h} t_{\mathrm{CPA}}
$$

\section{B. Safety Boundaries for Mid-Air Encounters}

As drawn in Fig. 3, the RTCA Special Committee 228 (SC-228) has determined two layers of critical UAS safety boundaries around the UA to quantitatively predict and resolve potential conflicts in mid-air encounters: the Near Mid-Air Collision (MNAC) boundary and the Well Clear (WC) boundary [8].

- The NMAC boundary is a standard cylinder: $500 \mathrm{ft}$ in radius horizontally, and $\pm 100 \mathrm{ft}$ in height vertically.

- The WC boundary is not only a spatial separation in range, but also a temporal separation in time [15, 16]. For example, during a head-on encounter, the radius of the WC cylinder in the front of the UA is a 35-second travel distance between the intruder and the UA, and the radius of the WC cylinder in the back of the UA is $4000 \mathrm{ft}$. In addition, the height of the WC cylinder is $\pm 450 \mathrm{ft}$ from the UA. 


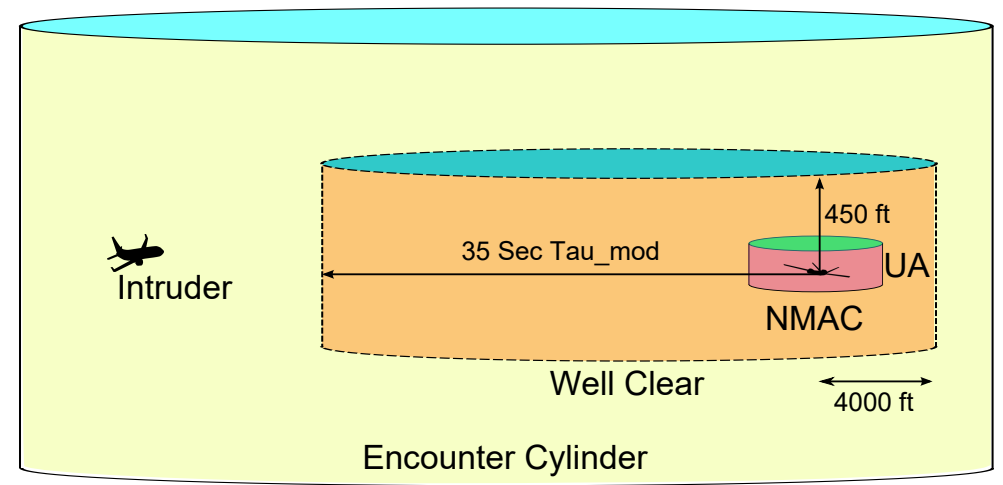

Fig. 3 Layered encounter cylinder diagram.

The formal definitions for NMAC and WC cylinders are given as follows:

Definition 1 (NMAC) The NMAC boundary is a standard cylinder around the UA. $R_{\mathrm{NMAC}}=500$ feet in radius horizontally, and $h_{\mathrm{NMAC}}= \pm 100$ feet in height vertically [8].

Definition 2 (WC) For given: Modified Range Tau Threshold $\tau_{\bmod _{\mathrm{wc}}}=35$ sec, Horizontal Miss Distance Threshold $H M D_{\mathrm{wc}}^{*}=D M O D_{\mathrm{wc}}=4000 \mathrm{ft}$, and Vertical Separation Threshold VMD $D_{\mathrm{wc}}^{*}=450 \mathrm{ft}$, an intruder is within WC $[8]$ when

$$
\left[0 \leq \tau_{m o d} \leq \tau_{\text {mod }_{\mathrm{wc}}}^{*}\right] \text {.and. }\left[H M D \leq H M D_{\mathrm{wc}}^{*}\right] \text {.and. }\left[V_{s} \leq V M D_{\mathrm{wc}}^{*}\right]
$$

where: $\tau_{\text {mod }}$ is the modified range tau defined in Eq. $10, H M D$ is the horizontal miss distance at the CPA defined in Eq. 13 and $V_{s}$ is the vertical separation that can be calculated by $V_{s}=a b s\left(d_{h}\right)$ with Eq. 3

\section{Control Zones for Mid-Air Encounters}

To prevent mid-air traffic from violating the safety boundaries, three control zones around the UA are proposed in Fig. 4. the hazard zone, the alert zone, and the safety zone. In this design: 1) when the traffic aircraft breaks into the hazard zone, the UA should take immediate maneuvers to avoid a potential Loss of Well Clear (LoWC); 2) when the traffic aircraft breaks into the alert zone, the UA may or may not respond to alerts from DAA systems, depending upon collision risk levels; and 3) when the traffic aircraft is outside of the alert zone, the UA is in the safety zone and can remain on the original flight course.

As depicted in Fig. 4, the safety zone in green refers to the areas outside the alert zone of the UA. The alert zone in yellow is a larger cylinder outside the hazard zone, which is defined as follows [8]:

Definition 3 (Alert Zone) For given: Modified Range Tau Threshold $\tau_{\text {mod }_{\mathrm{Az}}}^{*}=110$ sec, Horizontal Miss Distance Threshold $H M D_{\mathrm{AZ}}^{*}=D M O D_{\mathrm{Az}}=2$ nmi, and Vertical Separation Threshold $V M D_{\mathrm{AZ}}^{*}=800 \mathrm{ft}$, an intruder is within the 


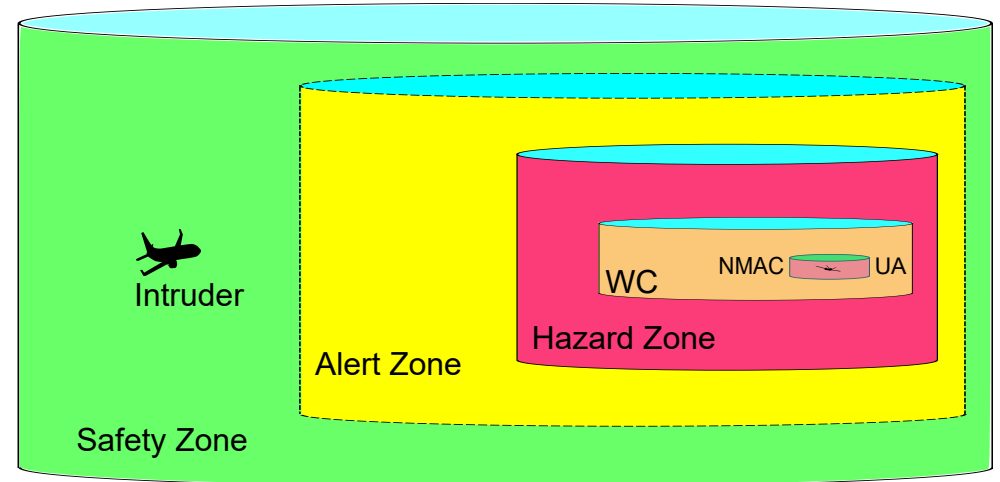

Fig. 4 Layered encounter zones of the UA.

alert zone when

$$
\left[0 \leq \tau_{\text {mod }} \leq \tau_{\text {mod }_{\mathrm{Az}}}^{*}\right] \text {.and. }\left[H M D \leq H M D_{\mathrm{Az}}^{*}\right] \text {.and. }\left[V_{s} \leq V M D_{\mathrm{Az}}^{*}\right]
$$

The hazard zone in red refers to a region outside the WC boundary and within the alert zone of the UA, which is a threshold boundary for the UA to trigger avoidance maneuvers. The methods to determine this threshold boundary will be given in details in Section III

\section{Mitigation Categories for Mid-Air Encounters}

In accordance with the layered zones in Fig. 4 , two categories of DAA mitigation solutions are designed in this paper to help small UAS avoid potential conflicts during mid-air encounters.

- Self-separation refers to efforts carried out by the PIC with the guidance from DAA systems to avoid LoWCs when traffic aircraft are penetrating the alert zone of the UA with LoWCs projected.

- Collision avoidance refers to maneuvers triggered by DAA systems to avoid NMACs when traffic aircraft have entered the hazard zone and are close to breaching the WC boundary of the UA with NMACs projected.

It should be pointed out that the TCAS has been designed to avoid potential mid-air conflicts by vertical maneuvers. In case of miscommunication with existing TCAS-equipped aircraft, DAA guidance systems for small UAS should choose horizontal maneuvers to avoid potential LoWCs in UAS self-separation [8].

\section{Mitigation Solution in Self-separation}

As discussed in Section 1 for effective or optimal maneuvering, the optimized guidance method is preferred in UAS self-separation; however, this method typically cannot be used to provide real-time DAA guidance for mid-air encounters since it often requires extra computation time to search for the best solutions from all possible maneuvering options (i.e., various maneuvering timings, turning directions, turn rates, and durations). To fix this issue, a learning-based decision tree method is proposed in this section to use knowledge learned from the previous successful maneuvering decisions 
studied in mid-air encounters, to help small UAS DAA systems select the optimized mitigation solutions in real-time for UAS self-separation.

\section{A. Knowledge base establishment}

As small UAS are light-weight (less than $25 \mathrm{~kg}$ ) and operate at a slow cruise airspeed (less 100 kt) [17], their turning trajectories and the time needed to complete turns vary in different wind conditions (i.e., different wind speed and wind directions). Thus, to quantitatively study small UAS maneuvering performance in winds, a Monte Carlo (MC) simulation-based algorithm is developed in this subsection to check small UAS horizontal maneuverabilities in various wind conditions, and then to determine the least horizontal maneuvering method for small UAS to retain WC at the closest range with oncoming traffic in each simulated mid-air encounter. Later, according to these collected maneuvering decisions, an encounter maneuvering guidance knowledge base is therefore established to help small UAS DAA systems determine appropriate maneuvers in future mid-air encounters.

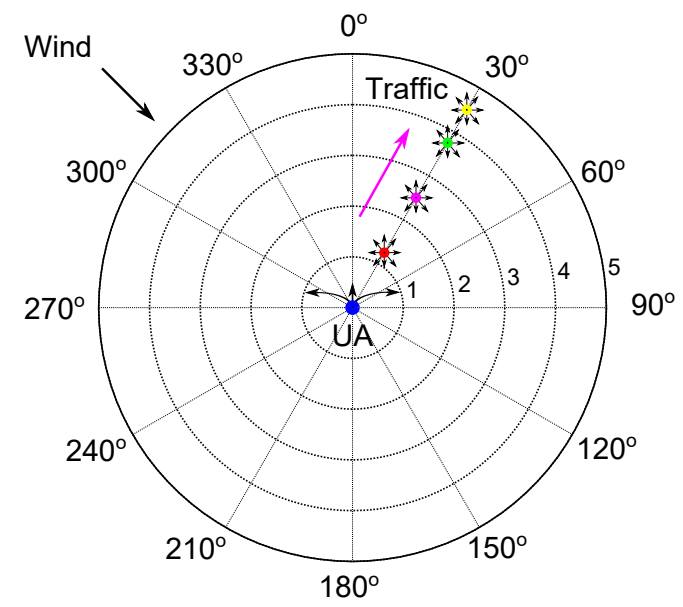

Fig. 5 A web structure used in the Monte Carlo simulation to determine the least maneuvering methods (bearing in deg and range in $\mathbf{n m i}$ ).

As shown in Fig. 5, a web structure is introduced in the algorithm design, where traffic aircraft are initiated from inner circles to outer circles at bearing angles $\left[0^{\circ}, 360^{\circ}\right)$ with heading angles in $\left[0^{\circ}, 360^{\circ}\right)$, and UA are initiated at the web center with the $0^{\circ}$ heading angle (to the north). At each bearing angle, we locate the shortest horizontal range between UA and traffic at which UA can avoid LoWCs with traffic in all possible headings by one of the appropriate horizontal maneuvers. In the implementation, for obtaining bounded results, the algorithm assumes that: 1) traffic are on level flights with constant horizontal velocities throughout mid-air encounters, and 2) UA are on level flights or level maneuvers to avoid LoWCs. Hence, the states of UA and traffic can be reduced to $[x, y, \psi, v, \dot{\psi}]$ for latitude, longitude, heading, horizontal velocity, and turn rate, and then the MC simulation procedures can be given as the following Algorithm 1 . 


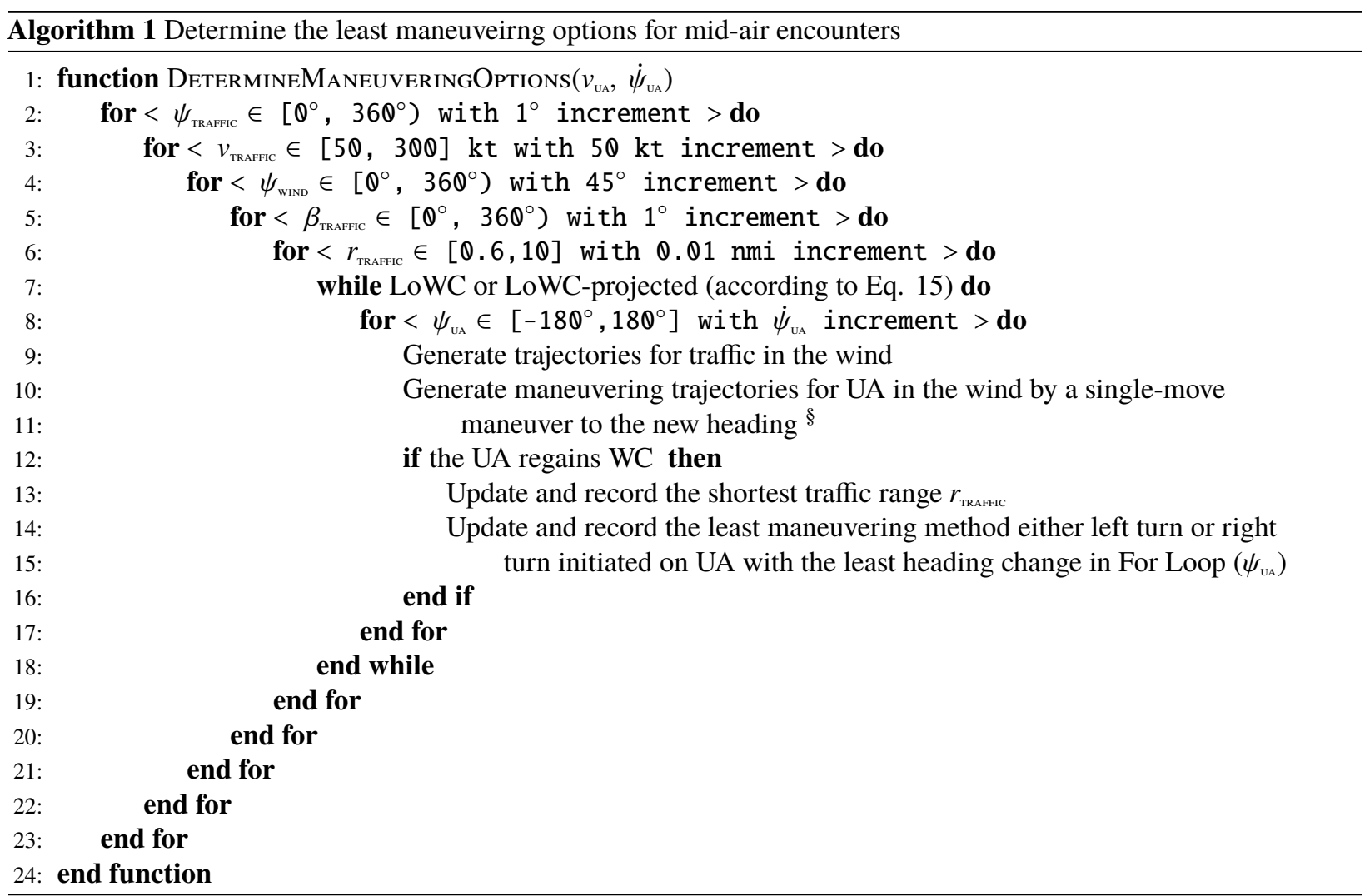

The parameters and settings used to implement Algorithm 1 are listed as follows:

- Based on the airspace in the low altitude below $5000 \mathrm{ft}$ at which small UA are most likely operated, we assume that small UA are operated at airspeed $v_{\mathrm{UA}}=75 \mathrm{kt}$ and turn rate $\dot{\psi}_{\mathrm{UA}}=6 \% \mathrm{sec}$.

- Traffic aircraft are simulated at an airspeed range of $[50,300] \mathrm{kt}$ with an airspeed increment every $50 \mathrm{kt}$.

- For LoWC, traffic aircraft are initiated at $0.6 \mathrm{nmi}$ (within $D M O D_{\mathrm{wc}}=0.66 \mathrm{nmi}=4000 \mathrm{ft}$ ) at a bearing angle $\beta_{\text {тRAFFC }}$ in $\left[0^{\circ}, 360^{\circ}\right)$ and move outer bound every $0.01 \mathrm{nmi}$ for each simulation run.

- The detected traffic bearing $\beta_{\text {твағғс }}$ and the traffic heading $\psi_{\text {твағті }}$ are selected every $1^{\circ}$ in $\left[0^{\circ}, 360^{\circ}\right)$.

- Winds are introduced at $20 \mathrm{kt}$ in eight directions every $45^{\circ}$ in $\left[0^{\circ}, 360^{\circ}\right)$.

Table 1 Datasets in the UA maneuvering knowledge base

\begin{tabular}{cc}
\hline Dataset & Parameters included \\
\hline Traffic & Velocity $\left(v_{\text {TRAFFC }}\right)$, Detected bearing $\left(\beta_{\text {TRA }}\right)$, Heading $\left(\psi_{\text {TRAFFC }}\right)$ \\
UA & Velocity $\left(v_{\mathrm{UA}}\right)$, Heading $\left(\psi_{\mathrm{UA}}\right)$ \\
Wind & Wind speed $\left(v_{\mathrm{wIND}}\right)$, Wind direction $\left(\psi_{\mathrm{WIND}}\right)$ \\
Maneuvering options & Turning direction, Heading change \\
Encounter states & Range minimum, Range rate, $H M D, \tau_{\text {mod }}$ \\
\hline
\end{tabular}

\footnotetext{
${ }^{\S}$ Small UA trajectory generation during level flights and horizontal maneuvers in the wind is based on the kinematics model discussed in [2] 18].
} 
Finally, in each simulated encounter throughout the MC simulation, the shortest traffic range and the least maneuvering method (left turn or right turn with the least heading change on the UA), as well as other related encounter parameters such as $v_{\mathrm{UA}}, \psi_{\mathrm{UA}}, v_{\mathrm{TRAFFIC}}, \psi_{\text {TRAFFIC }}, \beta_{\text {TRAFFIC }}, v_{\mathrm{wind}}, \psi_{\mathrm{wind}}, H M D$, and $\tau_{\text {mod }}$, are saved in a SQLite local database [19], as listed in Table 1, to form an optimized maneuvering guidance knowledge base for further decision making.

\section{B. Maneuvering knowledge learning}

As learned from the design strategies of TCAS and AlphaGo, we need to reduce the breadth of the decision tree (i.e., decision options at each choice point on the decision tree) for real-time decision making. In response to this request, we first design seven horizontal maneuvering options in various turn rates as listed in Table 2 for UA to handle collision risks from low to high risk levels during mid-air encounters.

Table 2 UA horizontal maneuvering options

\begin{tabular}{cccccc}
\hline $\begin{array}{c}\text { Suggested heading } \\
\text { changes }(\mathrm{deg})\end{array}$ & $\begin{array}{c}\text { Collision } \\
\text { risks }\end{array}$ & $\begin{array}{c}\text { Maneuvering } \\
\text { options }\end{array}$ & $\begin{array}{c}\text { Heading changes } \\
(\mathrm{deg})\end{array}$ & $\begin{array}{c}\text { Turn rate } \\
(\mathrm{deg} / \mathrm{sec})\end{array}$ & $\begin{array}{c}\text { Duration } \\
(\mathrm{sec})\end{array}$ \\
\hline & & & & & \\
{$[-180,-60]$} & High & $L 3$ & -60 & -6 & 10 \\
$(-60,-30]$ & Medium & $L 2$ & -30 & -3 & 10 \\
$(-30,0)$ & Low & $L 1$ & -15 & -1.5 & 10 \\
0 & Negligible & Level & 0 & 0 & 10 \\
$(0,30)$ & Low & $R 1$ & 15 & 1.5 & 10 \\
{$[30,60)$} & Medium & $R 2$ & 30 & 3 & 10 \\
{$[60,180]$} & High & $R 3$ & 60 & 6 & 10
\end{tabular}

Note: negative figures signify a left turn, and positive figures are for a right turn; assume that a maximum $6 \mathrm{deg} / \mathrm{sec}$ level turn can be performed on the UA during operations.

Secondly, we design a supervised learning method to extract the maneuvering experience from the knowledge base established in Table 1, and then construct a policy network, in terms of the newly-designed horizontal maneuvering options in Table 2 to further reduce the decision options on the decision tree and guide approriate horizontal maneuvers in future mid-air encounters. For example, when the encounter input conditions are determined (e.g., Traffic states: velocity at $100 \mathrm{kt}$, detected bearing at $30^{\circ}$, and heading to $225^{\circ}$; UA states: velocity at $75 \mathrm{kt}$ and heading to $0^{\circ}$; and wind conditions: speed at $20 \mathrm{kt}$ and direction to $0^{\circ}$ ), the suggested maneuvering option (i.e., the turning direction and the heading change) can be obtained from the knowledge base via a database querying operation (e.g., left turn and $36^{\circ}$ heading change), and this suggestion is therefore adopted in the policy network for future similar mid-air encounters.

However, in most cases, input conditions cannot be determined in as much detail as this example due to measurement uncertainties. As a result, database range querying operations are employed to retrieve all suggested heading changes from the knowledge base, and then the most probable maneuvering option (i.e., the highest likelihood from all suggested options) is selected for UA to handle measurement uncertainties during mid-air encounters. For instance, when the 
detected traffic bearing is at $30^{\circ} \pm 5^{\circ}$ and the traffic relative heading is at $225 \pm 5^{\circ}$, the range querying operation is performed with the detected traffic bearing $\beta_{\text {тrafic }} \in\left[25^{\circ}, 35^{\circ}\right]$ and the traffic relative heading $\psi_{\text {Traffic }} \in\left[220^{\circ}, 230^{\circ}\right]$ in the database, and then 81 corresponding database records are obtained as listed in Table 3 .

Table 3 A sample database range query result from the knowledge base.

\begin{tabular}{ccccc}
\hline No & ID & Range rate $(\mathrm{kt})$ & Heading change (deg) & Range minimum (nmi) \\
\hline & & & & \\
1 & 477747 & -166.56 & -36 & 1.86 \\
2 & 477748 & -166.19 & -36 & 1.85 \\
3 & 477749 & -165.76 & -30 & 1.85 \\
4 & 477750 & -165.29 & -30 & 1.85 \\
5 & 477751 & -164.76 & -30 & 1.84 \\
6 & 477752 & -164.19 & -24 & 1.84 \\
$\vdots$ & $\vdots$ & $\vdots$ & $\vdots$ & $\vdots$ \\
76 & 495030 & -163.65 & -42 & 1.83 \\
77 & 495031 & -163.33 & -42 & 1.83 \\
78 & 495032 & -162.96 & -36 & 1.83 \\
79 & 495033 & -162.55 & -36 & 1.82 \\
80 & 495034 & -162.08 & -30 & 1.82 \\
81 & 495035 & -161.56 & -30 & \\
\hline
\end{tabular}

Table 4 Maneuvering options statistics

\begin{tabular}{|c|c|c|c|c|}
\hline $\begin{array}{l}\text { Suggested heading } \\
\text { changes (deg) }\end{array}$ & $\begin{array}{c}\text { Probable maneuvers } \\
\text { likelihood }\end{array}$ & $\begin{array}{c}\text { Maneuvering } \\
\text { options }\end{array}$ & $\begin{array}{c}\text { Maneuvering } \\
\text { index }\end{array}$ & $\begin{array}{c}\text { Most probable } \\
\text { maneuvers }\end{array}$ \\
\hline$[-180,-60]$ & Num $_{L 3} /$ Num $_{\text {total }}$ & $L 3$ & -3 & \\
\hline$(-60,-30]$ & $\mathrm{Num}_{L 2} / \mathrm{Num}_{\text {total }}$ & $L 2$ & -2 & $\begin{array}{l}\text { (e.g., } \checkmark \text { if } \frac{N u m_{L 2}}{N u m_{\text {total }}} \text { is the } \\
\text { highest likelihood ratio.) }\end{array}$ \\
\hline$(-30,0)$ & Num $_{L 1} /$ Num $_{\text {total }}$ & $L 1$ & -1 & \\
\hline 0 & Num $_{\text {Level }} /$ Num $_{\text {total }}$ & Level & 0 & \\
\hline$(0,30)$ & $\mathrm{Num}_{R 1} /$ Num $_{\text {total }}$ & $R 1$ & 1 & \\
\hline$[30,60)$ & $\mathrm{Num}_{R 2} / \mathrm{Num}_{\text {total }}$ & $R 2$ & 2 & \\
\hline$[60,180]$ & $\mathrm{Num}_{R 3} / \mathrm{Num}_{\text {total }}$ & $R 3$ & 3 & \\
\hline
\end{tabular}

Once a list of suggested heading changes is obtained, such as the list in Table 3 , a likelihood analysis in Table 4 is introduced to summarize these suggested heading changes in seven angle regions (i.e., in $\left[-180^{\circ},-60^{\circ}\right],\left(-60^{\circ},-30^{\circ}\right]$, $\left(-30^{\circ}, 0^{\circ}\right), 0^{\circ},\left(0^{\circ}, 30^{\circ}\right),\left[30^{\circ}, 60^{\circ}\right)$, and $\left.\left[60^{\circ}, 180^{\circ}\right]\right)$ with respect to seven predefined maneuvering options in Table 2 (i.e., $L 3, L 2, L 1$, Level, $R 1, R 2$, and $R 3$ ). Finally, the suggested maneuvering option is chosen based on the highest likelihood ratio among seven maneuvering options (e.g., L2 suggested in Table 4 for UA to avoid LoWCs or NMACs during mid-air encounters. 
In summary, this training process through the supervised learning can be listed as follows:

1) Select a set of initial conditions for the UA and traffic in a mid-air encounter and perform a range querying operation in the database with sensor measurement uncertainties, e.g., UA velocity $\pm 10 \mathrm{kt}$, traffic velocity \pm 20 kt, detected traffic relative bearing $\pm 5^{\circ}$, traffic relative heading $\pm 5^{\circ}$, wind speed $\pm 10 \mathrm{kt}$, and wind direction $\pm 20^{\circ}$, to acquire a list of suggested maneuvering options from the knowledge base, as depicted in Table 3 .

2) Perform the likelihood analysis of suggested maneuvering options on the list, i.e., they are counted by heading changes in seven angle regions. For example, if one of the suggested maneuvering options on the list has a heading change at $-36^{\circ}$ in $\left(-60^{\circ},-30^{\circ}\right.$ ], then the likelihood counter $N u m_{L 2}$ is increased by 1 (i.e., $\left.N u m_{L 2}=N u m_{L 2}+1\right)$.

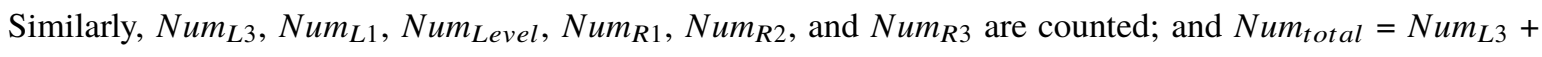
$N_{u m}+\operatorname{Num}_{L 1}+$ Num $_{\text {Level }}+N_{u m_{R 1}}+N_{u m_{R 2}}+N_{u m}{ }_{R 3}$.

3) The most probable maneuver on the list (with the highest likelihood ratio) is selected as the suggested maneuvering option to construct the policy network for the mid-air encounter defined in Step 1. For example, in Table 4 L2 is selected when $\frac{N u m_{L 2}}{N_{\text {um }} \text { total }}$ is the highest likelihood ratio among seven maneuvering options.

To construct the entire policy network in accord with all previously studied mid-air encounters in Subsection A, we design and carry out an MC tree search (using the above SL training process) throughout the entire knowledge base at a predefined resolution (i.e., every $1^{\circ}$ for relative bearings and relative headings from $0^{\circ}$ to $360^{\circ}$, every $50 \mathrm{kt}$ for velocities from $50 \mathrm{kt}$ to $300 \mathrm{kt}, 20 \mathrm{kt}$ wind in every $45^{\circ}$ from $0^{\circ}$ to $360^{\circ}$ ). It is true that the $\mathrm{MC}$ tree search requires a large amount of processing time for the millions of range querying operations in the database; however, once the SL training process is completed, the trained policy network can be loaded into the computer memory (RAM) to provide real-time supervisory guidance for decision making at each choice point on the decision tree, as captured in Fig. 6

Fig. 6 shows a series of trained policy network diagrams drawn on the 2D colormaps for UA maneuvering options in various velocities and wind conditions, where the vertical axis is traffic headings $\left[0^{\circ}, 360^{\circ}\right)$; the horizontal axis is traffic-detected bearings $\left[0^{\circ}, 360^{\circ}\right.$ ); and maneuvering options are colored as their indexes given in Table 4 (i.e., negative indexes for left turns in cool colors and positive indexes for right turns in warm colors). Figs. 6a 6a 6e, and 6g are policy network diagrams for traffic at various velocities in $20 \mathrm{kt}$ gusty south wind (direction at $0^{\circ}$ ), where most maneuvering options are given in symmetric. Figs. 6b 6d, 6f] and 6hare policy network diagrams for traffic at various velocities in $20 \mathrm{kt}$ gusty southwest wind (direction at $45^{\circ}$ ), where most maneuvering options are not in symmetric (with left shifts), in comparison with the ones in $20 \mathrm{kt}$ gusty south wind (direction at $0^{\circ}$ ). 


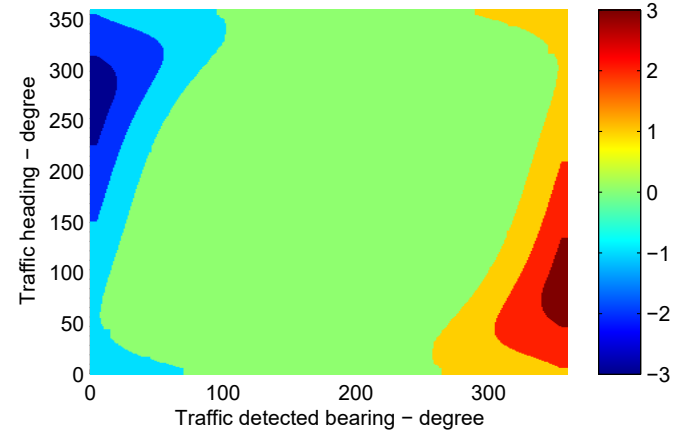

(a) $50 \mathrm{kt}$ traffic in $20 \mathrm{kt}$ gusty wind at $0^{\circ}$

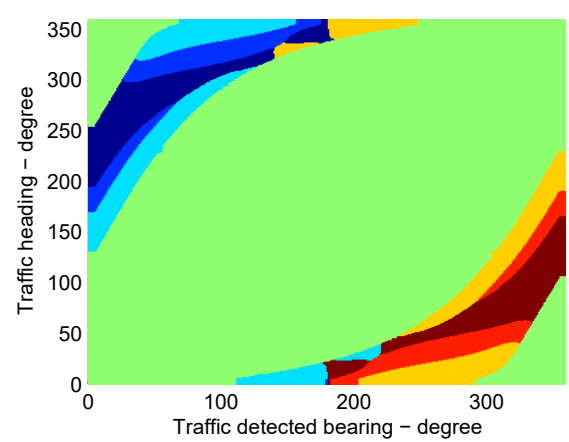

(c) $100 \mathrm{kt}$ traffic in $20 \mathrm{kt}$ gusty wind at $0^{\circ}$

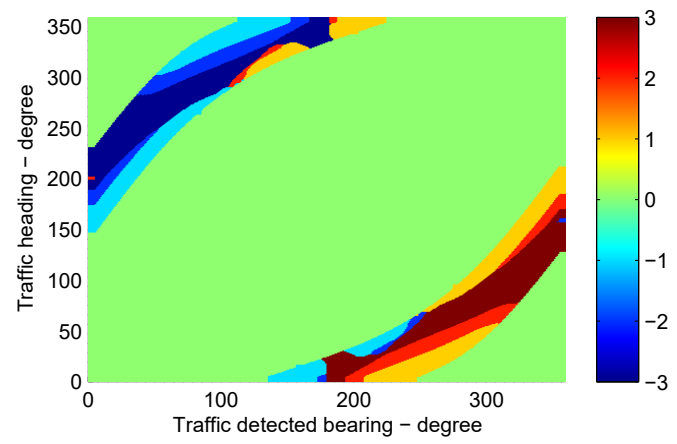

(e) $150 \mathrm{kt}$ traffic in $20 \mathrm{kt}$ gusty wind at $0^{\circ}$

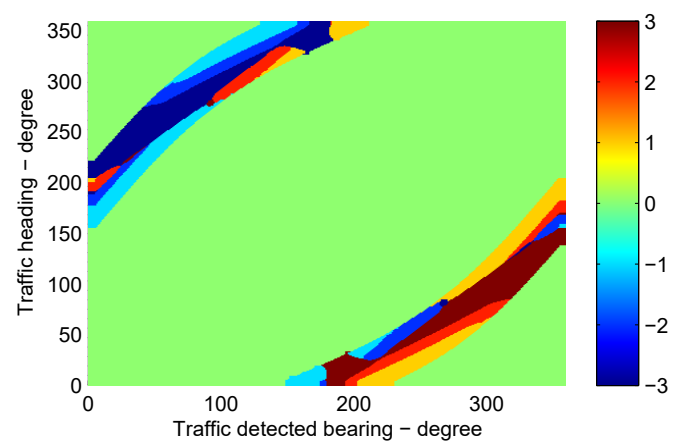

(g) $200 \mathrm{kt}$ traffic in $20 \mathrm{kt}$ gusty wind at $0^{\circ}$

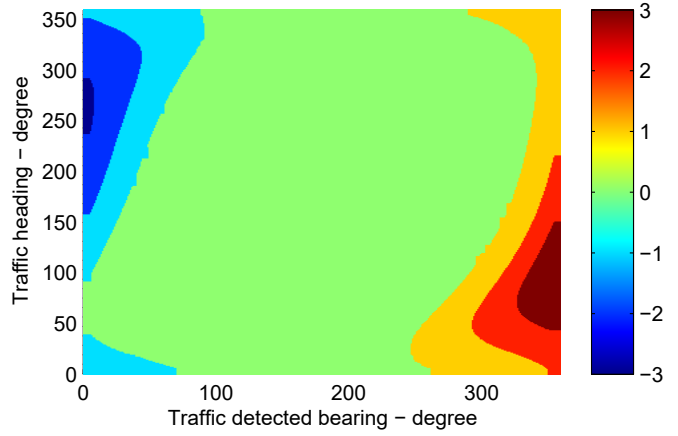

(b) $50 \mathrm{kt}$ traffic in $20 \mathrm{kt}$ gusty wind at $45^{\circ}$

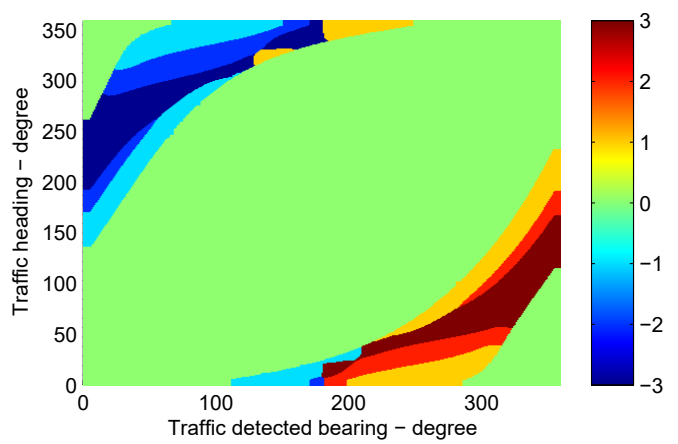

(d) $100 \mathrm{kt}$ traffic in $20 \mathrm{kt}$ gusty wind at $45^{\circ}$

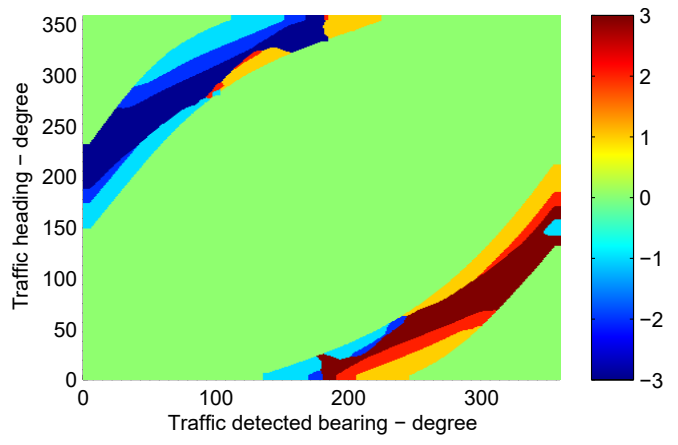

(f) $150 \mathrm{kt}$ traffic in $20 \mathrm{kt}$ gusty wind at $45^{\circ}$

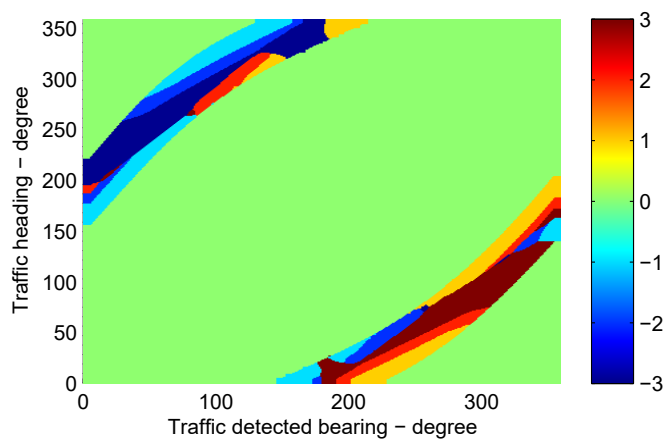

(h) $200 \mathrm{kt}$ traffic in $20 \mathrm{kt}$ gusty wind at $45^{\circ}$

Fig. 6 Sample policy network diagrams for UA maneuvering options in various velocities and wind conditions (UA: velocity at $75 \mathrm{kt}$ and heading to the north). 


\section{Collision risk assessment metrics}

In Subsection B we have constructed a policy network to reduce the breadth of the decision tree at each choice point on the decision tree. As learned from AlphaGo, to further reduce the depth of the decision tree and to provide online supervisory guidance for small UAS self-separation, we also need to design a value network to evaluate the collision risk changes among all the suggested maneuvering solutions on the decision tree, and then determine the appropriate maneuvering solutions with the best suitable maneuvering timing and choices for small UAS self-separation guidance in mid-air encounters. To reflect this requirement, a computable collision risk evaluation method is introduced for establishing the value network to carry out real-time collision risk assessment on the decision tree [2]. As depicted in Fig. (7) this method is based on encounter penetration severities from low risks (e.g., benign LoWC) to high risks (e.g., NMAC) in mid-air encounters, i.e., the severity of penetrating the alert zone (SPenAZ) around the UA, which consists of two independent risk level predictions: the penetration risk level and the range risk level.
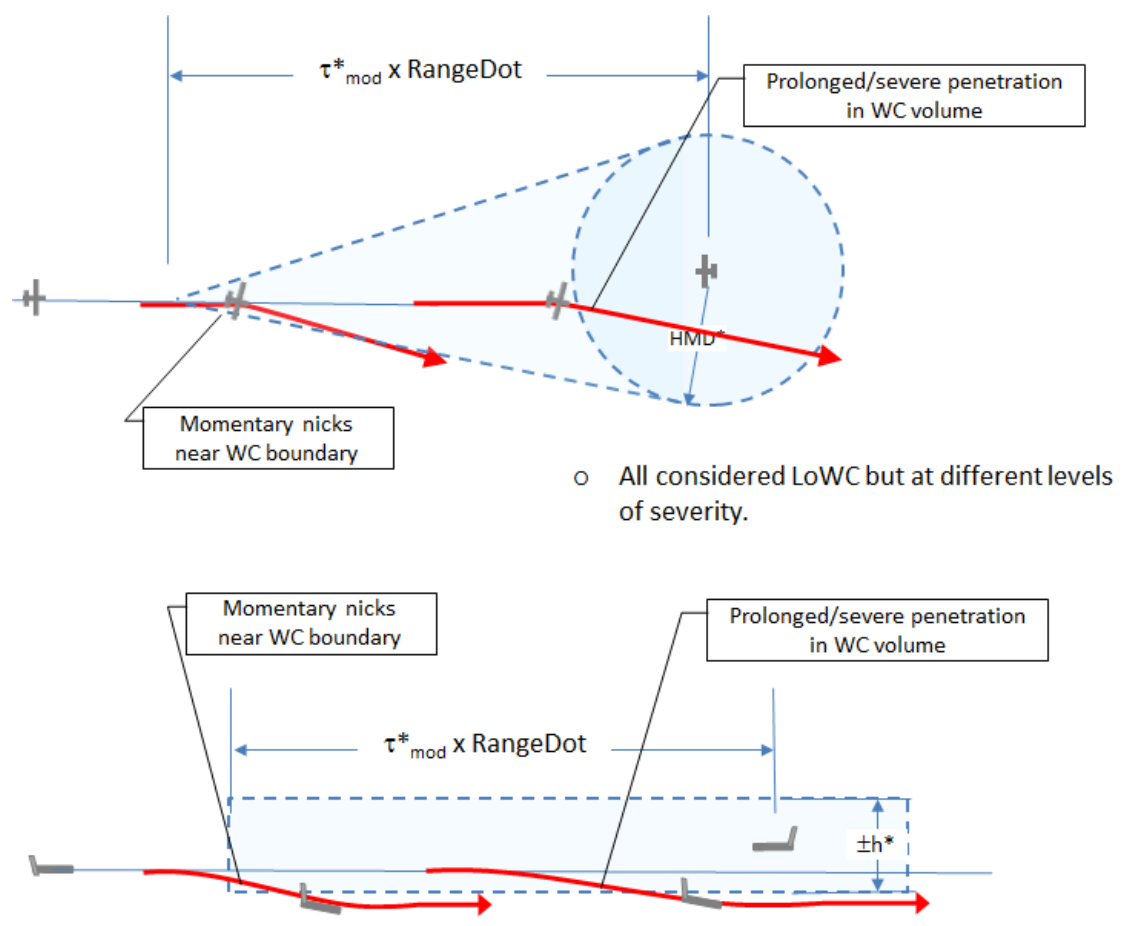

Fig. 7 Benign momentary nick at the LoWC boundary and prolonged, severe LoWC [8].

\section{Penetration risk level}

Similar to the Definition 3 (Alert Zone) in Section $[$ and the calculation equations for the severity of LoWC in [8], we employ all three encounter penetration components: the time penetration $\left(\tau_{m o d}\right)$, the horizontal penetration $(H M D)$, and the vertical penetration $\left(V_{s}\right)$, to quantitatively assess the penetration risk level, $P_{\text {risk }}$ (Penetration), throughout the 
duration when traffic are penetrating the alert zone of small UA, as follows:

$$
\begin{gathered}
P_{\text {risk }}(\text { Penetration })=1-\left(\bar{P}_{\text {risk }}\left(\tau_{\text {mod }}\right) \oplus \bar{P}_{\text {risk }}(H M D) \oplus \bar{P}_{\text {risk }}\left(V_{s}\right)\right) \\
\bar{P}_{\text {risk }}\left(\tau_{\text {mod }}\right)= \begin{cases}\min \left(\frac{\tau_{\text {mod }}-\tau_{\text {mod }}^{*}}{\left.\tau_{\text {wod }}^{*}, 1\right)}\right. & \text { if } \tau_{\text {mod }}>\tau_{\text {mod }_{\mathrm{wc}}}^{*} \\
1 & \text { if } \tau_{\text {mod }}<0 \\
0 & \text { Otherwise }\end{cases} \\
\bar{P}_{\text {risk }}(H M D)= \begin{cases}\min \left(\frac{H M D-R_{\mathrm{NMAC}}}{D M O D_{\mathrm{Az}}}, 1\right) & \text { if HMD }>R_{\mathrm{NMAC}} \\
0 & \text { Otherwise }\end{cases} \\
\bar{P}_{\text {risk }}\left(V_{s}\right)= \begin{cases}\min \left(\frac{V_{s}-h_{\mathrm{NMAC}}}{V M D_{\mathrm{wc}}^{*}+V M D_{\mathrm{Az}}^{*}}, 1\right) & \text { if } V_{s}>h_{\mathrm{NMAC}} \\
0 & \text { Otherwise }\end{cases}
\end{gathered}
$$

where: $P_{\text {risk }}($ Penetration $) \in[0,1], \bar{P}_{\text {risk }}\left(\tau_{\text {mod }}\right) \in[0,1], \bar{P}_{\text {risk }}(H M D) \in[0,1], \bar{P}_{\text {risk }}\left(V_{s}\right) \in[0,1]$, and the Fernandez-Guasti (FG) squircle operators $(\oplus)$ refer to FG Norm operations (in Appendix A) for risk synthesis to combine three normalized penetration components of collision risk levels.

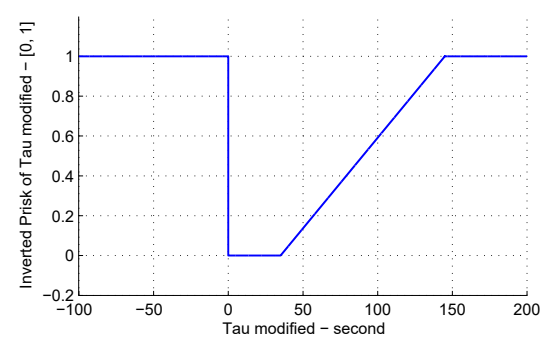

(a) $\bar{P}_{\text {risk }}\left(\tau_{\text {mod }}\right)$

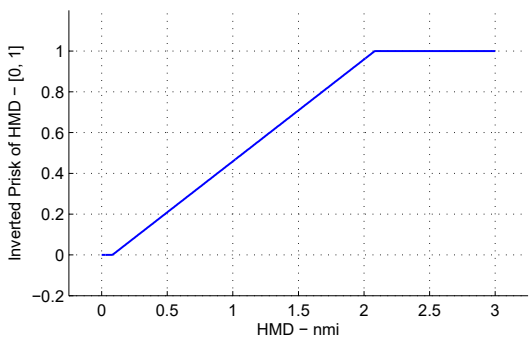

(b) $\bar{P}_{\text {risk }}(H M D)$

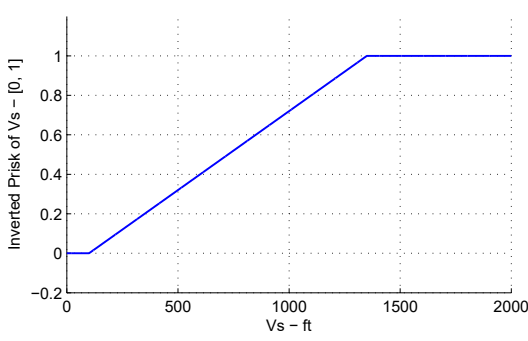

(c) $\bar{P}_{r i s k}\left(V_{S}\right)$

Fig. 8 Diagrams of $\bar{P}_{r i s k}\left(\tau_{m o d}\right), \bar{P}_{r i s k}(H M D)$, and $\bar{P}_{r i s k}\left(V_{s}\right)$ function curves.

Based on Eq. 18, Eq. 19, and Eq. 20, three function curves of inverted risk levels $\bar{P}_{\text {risk }}\left(\tau_{\text {mod }}\right), \bar{P}_{\text {risk }}(H M D)$, and $\bar{P}_{\text {risk }}\left(V_{s}\right)$ are plotted in Fig. 8 In Fig. $8 \mathrm{a} . \bar{P}_{\text {risk }}\left(\tau_{m o d}\right)=1$ when traffic are not on the closing geometry with small UA $\left(\tau_{\text {mod }}<0 \mathrm{sec}\right)$ or on the closing geometry but $\tau_{\text {mod }}>145 \mathrm{sec} . \bar{P}_{\text {risk }}\left(\tau_{\text {mod }}\right)=0$ when traffic are on the closing geometry and $\tau_{\text {mod }}<35$ sec. $\bar{P}_{\text {risk }}\left(\tau_{\text {mod }}\right)$ is linearly increased from 0 to 1 when $\tau_{\text {mod }} \in[35,145]$ sec; namely, $\bar{P}_{\text {risk }}\left(\tau_{\text {mod }}\right)$ is decreasing while $\tau_{\text {mod }}$ decreases (i.e., when traffic are approaching small UA).

In Fig. $8 \mathrm{~b} \bar{P}_{\text {risk }}(H M D)=1$ when the projected $H M D$ is larger than $2.08 \mathrm{nmi}(2 \mathrm{nmi}+500 \mathrm{ft}=2.08 \mathrm{nmi})$. $\bar{P}_{\text {risk }}(H M D)=0$ when traffic are projected within the range of $500 \mathrm{ft}(0.08 \mathrm{nmi})$ with small UA on the horizontal plane. $\bar{P}_{\text {risk }}(H M D)$ is linearly increased from 0 to 1 when $H M D \in[0.08,2.08]$ nmi; namely, $\bar{P}_{\text {risk }}(H M D)$ is lower for 
smaller $H M D$ (i.e., small UA and traffic are projected closer at the CPA on the horizontal plane).

In Fig. $8 \mathrm{c} . \bar{P}_{\text {risk }}\left(V_{s}\right)=1$ when the vertical separation $V_{s}$ is larger than $1250 \mathrm{ft}$. $\bar{P}_{r i s k}\left(V_{s}\right)=0$ when traffic are within a 100-ft vertical separation with small UA in altitude. $\bar{P}_{r i s k}\left(V_{s}\right)$ is linearly increased from 0 to 1 when $V_{s} \in[100,1250]$ $\mathrm{ft}$; namely, $\bar{P}_{r i s k}\left(V_{s}\right)$ is lower for the smaller vertical separation $V_{s}$ (i.e., small UA and traffic are closer on the vertical plane).

In Eq. 17. as discussed in Appendix B, three normalized and inverted risk levels, $\bar{P}_{r i s k}\left(\tau_{m o d}\right), \bar{P}_{r i s k}(H M D)$, and $\bar{P}_{r i s k}\left(V_{s}\right)$ are combined together to calculate the penetration risk level, $P_{\text {risk }}$ (Penetration), in a mid-air encounter, and

- $\left[P_{\text {risk }}(\right.$ Penetration $\left.) \rightarrow 0\right]$ refers to a low collision risk level as traffic aircraft starts penetrating the UA alert zone.

- $\left[P_{\text {risk }}(\right.$ Penetration $\left.) \rightarrow 1\right]$ means that the risk level for a potential NMAC is high.

The detailed description for the $P_{\text {risk }}$ (Penetration) value range is listed as follows:

Table 5 Description for $P_{\text {risk }}($ Penetration $)$ value range

\begin{tabular}{cc}
\hline $\begin{array}{c}P_{\text {risk }}(\text { Penetration }) \\
{[0,0.5)}\end{array}$ & $\begin{array}{c}\text { Description for parameter value range } \\
\text { Penetrating the alert zone, but always remaining WC } \\
\text { Penetrating the alert zone, with potential LoWC, } \\
\text { at the time to breach the edge of the Hazard Zone } \\
\text { (a critical boundary between WC and Benign LoWC) }\end{array}$ \\
& $\begin{array}{c}\text { Penetrating the alert zone, with potential LoWC / already LoWC } \\
\text { LoWC from the least severe to the most severe (WC to NMAC) }\end{array}$ \\
\hline
\end{tabular}

As described in Table 5 . $P_{\text {risk }}($ Penetration $)=0.5$ is designed as a critical risk level threshold, $P_{\text {risk }}($ Threshold $)$ 团 to distinguish the collision risks between WC and LoWC, thus this threshold can be used to locate the boundary of the UA hazard zone and help DAA systems determine the maneuvering time to initialize the required self-separation maneuvers during mid-air encounters.

\section{Range risk level}

For most head-on encounters, the penetration risk level $P_{\text {risk }}$ (Penetration) in Eq. 17 can be used to evaluate collision risk levels between the UA and traffic; however, for tail-chase encounters with very small closing velocities, $\tau_{\text {mod }}$ may still be larger than $\tau_{m o d_{A z}}^{*}(110 \mathrm{sec})$, even when traffic aircraft close to the UA $D M O D_{\mathrm{wc}}$ boundary (4000 ft), e.g., a tail-chase encounter with a UA at $75 \mathrm{kt}$ and traffic at 76kt (i.e., a UA overtaken encounter with a $1 \mathrm{kt}$ closing velocity). Therefore, the calculated penetration risk level cannot be used to represent collision risk levels for encounters with small closing velocities. To remedy this issue, we introduce a new severity metric, the range risk level, $P_{\text {risk }}($ Range $)$, to evaluate collision risks based on the horizontal range $r$ regardless of the $\tau_{\text {mod }}$ calculated during mid-air encounters.

\footnotetext{
"Note that $P_{\text {risk }}($ Threshold $)=0.5$ is a design preference in this paper, and the PIC can choose another preferable risk level threshold (e.g., $P_{\text {risk }}($ Threshold $\left.) \in[0.45,0.55]\right)$ depending on safety concerns and flight missions planned in UAS operations.
} 


$$
P_{\text {risk }}(\text { Range })= \begin{cases}1-\min \left(\frac{r-2 D M O D_{\mathrm{wc}}}{2 D M O D_{\mathrm{wc}}}, 1\right) & \text { if } r>2 D M O D_{\mathrm{wc}} \text { and } V_{s} \leq V M D_{\mathrm{Az}}^{*} \\ 1 & \text { if } r \leq 2 D M O D_{\mathrm{wc}} \text { and } V_{s} \leq V M D_{\mathrm{Az}}^{*} \\ 0 & \text { Otherwise }\end{cases}
$$

where $P_{\text {risk }}($ Range $) \in[0,1], D M O D_{\text {wc }}=4000 \mathrm{ft}, V M D_{A z}^{*}=800 \mathrm{ft}, r$ is the current horizontal range between the UA and traffic, and $V_{s}$ is the current vertical separation between the UA and traffic. Similarly, the range risk level $P_{\text {risk }}($ Range $)=P_{\text {risk }}($ Threshold $)=0.5$ can be used to determine a minimum-size hazard zone, i.e., a cylinder with 2 $\mathrm{nmi}\left(D M O D_{\mathrm{Az}}\right)$ in radius horizontally and $\pm 800 \mathrm{ft}\left(V M D_{\mathrm{Az}}^{*}\right)$ in height vertically, around the UA.

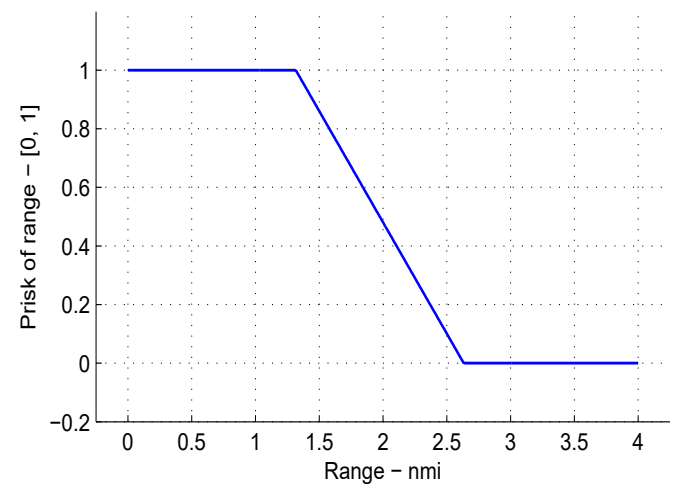

(a) View in 2D

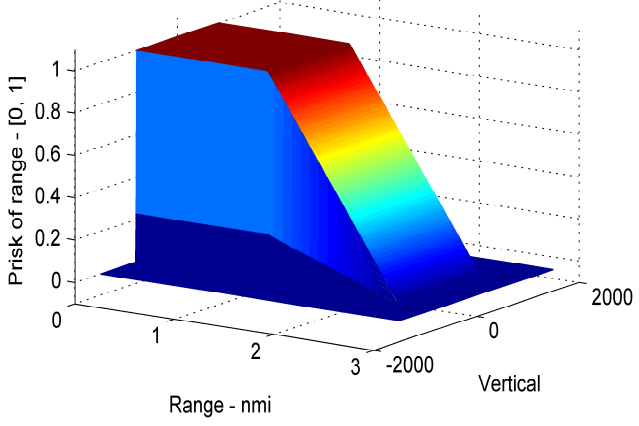

(b) View in 3D

Fig. 9 Diagrams of $P_{\text {risk }}($ Range $)$ function curves.

\section{Collision risk level}

The collision risk level, $P_{\text {risk }}($ Collision $)$, can be defined as the larger one between two independent risk levels: $P_{\text {risk }}($ Penetration $)$ and $P_{\text {risk }}($ Range $)$, as

$$
P_{\text {risk }}(\text { Collision })=\operatorname{SPenAZ}=\max \left(P_{\text {risk }}(\text { Penetration }), P_{\text {risk }}(\text { Range })\right)
$$

Finally, with the $P_{\text {risk }}($ Collision $) \in[0,1]$ in Eq. 22, the value network can be constructed to help small UAS DAA systems assess collision risks during mid-air encounters, evaluate mitigation performance of suggested maneuvering options on the decision tree, and select appropriate maneuvering options to guide small UAS self-separation when the traffic is penetrating the alerting zone of the UA (e.g., when $P_{\text {risk }}($ Collision $\left.) \geq 0.5\right)$.

\section{Smart decision tree method}

Based on the policy network and the value network developed in the previous subsections, we propose a smart decision tree method (SDTM) in this subsection to provide real-time manevering guidance for small UAS self-separation. 
As shown in Fig. 10, a binary decision tree is constructed, where choice points on the decision tree are set at every time interval (i.e., $\Delta t=10 \mathrm{sec}$ ) because the UA typically needs extra time to settle down with state changes in case of a loss of controllability or stabilizability. At each choice point (CP), the UA has two options: either taking a maneuver suggested by the policy network (1), or remaining on/returning to the level flight (0). In addition, the decision tree is constructed in three to six hierarchies upon mitigation performance evaluation results from the value network, which is in accord with the self-separation alerting time by the default entry condition when $P_{\text {risk }}($ Collision) $\geq 0.5$ (i.e., 30 to 60 seconds before LoWCs or NMACs).

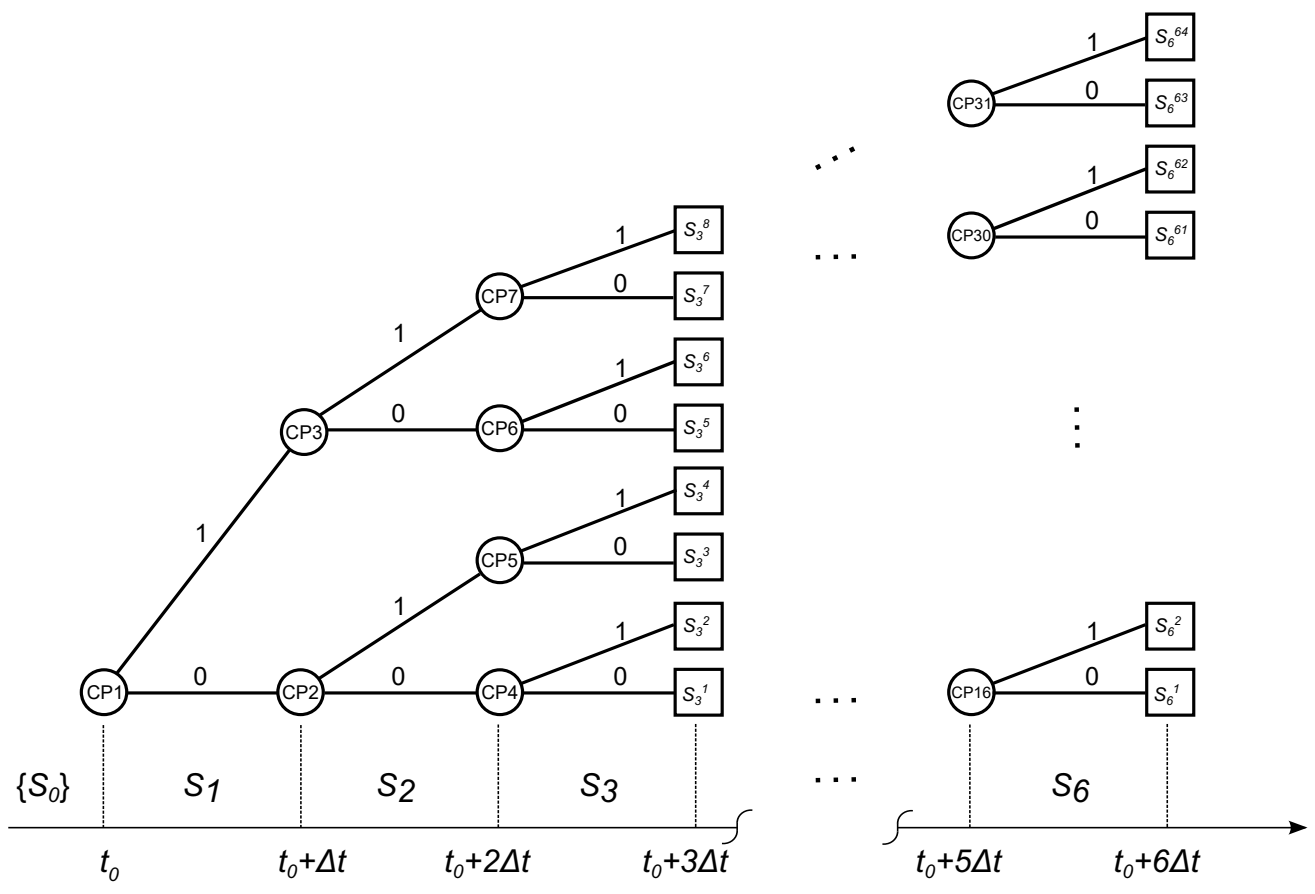

Fig. 10 An execution of a decision tree with choice points at time interval $\Delta t$.

The learning-based SDTM is designed as follows:

\section{System Inputs}

Traffic states $X_{\text {TRAFIC } n_{n}}=\left[x_{\text {TRAFFIC }_{n}}, y_{\text {TRAFFic }_{n}}, h_{\text {TRAFFIC }_{n}}, v_{\text {TRAFFI }_{x}, n}, v_{\text {TRAFFIC } y, n_{n}}, v_{\text {TRAFFIC }_{h}, n}\right]^{T}$,

UA states $X_{\mathrm{UA} n}=\left[x_{\mathrm{UA} n}, y_{\mathrm{UA} n}, h_{\mathrm{UA} n}, v_{\mathrm{UA} x, n}, v_{\mathrm{UA} y, n}, v_{\mathrm{UA} h, n}\right]^{T}$,

UA horizontal airspeed $v_{\mathrm{UA}, \mathrm{A} \mathrm{S}_{n}}$,

estimated wind speed $v_{\mathrm{ws}_{n}}$, estimated wind direction $\psi_{\mathrm{wiND}_{n}}$,

detected traffic bearing with respect to the UA $\beta_{\text {твағFі } n}$,

horizontal range $r_{n}$, time penetration $\tau_{\bmod _{n}}$, horizontal penetration $H M D_{n}$, vertical penetration $V_{s_{n}}$, and collision risk level $P_{\text {risk }}(\text { Collision })_{n}$ at the time step $n$. 


\section{Control Variables}

Generally, maneuvering states are $\mathbf{m}=\left[\dot{v}, \dot{h}, \dot{\psi}, t_{m}\right]$ for horizontal acceleration, vertical rate, turn rate, and time duration for maneuvering, respectively. During UAS self-separation, horizontal maneuvers are selected, so maneuvering states can be simplified as $\mathbf{m}=\left[\dot{\psi}, t_{m}\right]$ with allowed horizontal maneuvering options listed in Table 2 .

\section{Specifications}

In the construction of the smart decision tree, the first specification is to provide consistent maneuvers for selfseparation guidance. For example, a left turn $L 1$ maneuver is initiated at the first choice point, and then no right turn maneuvers will be selected at other choice points on the decision tree. The allowed maneuvering options are limited to left turns $L 1, L 2, L 3$, and the level flight Level.

The second specification is to determine emergency shutdown conditions for self-separation mitigation. When traffic aircraft are approaching the WC boundary in the hazard zone and NMACs are projected, small UAS should exit from self-separation mitigation and enter collision avoidance mitigation to avoid coming NMACs.

\section{Decision Tree Constructions}

When self-separation mitigation is enabled, decision trees are constructed to predict encounter states from the present to the lookahead horizon (e.g., $3 \Delta t=30 \mathrm{sec}$ ) during mid-air encounters [20]. As shown in Fig. 10, the policy network is used to determine maneuvering options at choice points on the decision tree; however, if the suggested maneuvering option is not consistent with the ones made at other choice points previously, an $L 1$ or $R 1$ maneuver will be selected to construct the decision tree upon maneuveing options selected at other choice points.

During the decision evaluation, predicted trajectories of both the UA and traffic for all suggested maneuvering options on the decision tree are generated under given wind conditions (based on the kinematics model discussed in [2, 18]). Moreover, decision trees are constructed dynamically (i.e., in various hierarchies) upon evaluation results by the value network. Thus, decision trees are first constructed at three hierarchies with eight suggested maneuvering options, and later they are expanded up to six hierarchies with 64 suggested maneuvering options when $P_{\text {risk }}(\text { Collision })_{\text {Predicted }}<0.5$ has not been achieved on three-level decision trees.

\section{System Outputs}

The learning-based SDTM outputs the predicted collision risk level $P_{\text {risk }}(\text { Collision })_{\text {Predicted }}$ and the predicted deviation (i.e., deviation distance and deviation angle) from the original flight course at the lookahead horizon (e.g., 30-second prediction in Fig. 11. In Table 6, sample analysis results of a three-level decision tree are listed for a head-on encounter in Fig. 12. To choose the best maneuvering options in Table 6 for UA to avoid potential LoWCs or NMACs, the DAA supervisory guidance should meet with the following conditions: 
1) The predicted collision risk level $P_{\text {risk }}(\text { Collision })_{\text {predicted }}<P_{\text {risk }}($ Threshold $)$ (0.5, the default collision risk level threshold).

2) The predicted $H M D_{\text {predicted }}>D M O D_{\mathrm{wc}}(0.66 \mathrm{nmi})$.

3) The predicted horizontal range $r_{\text {predicted }}>D M O D_{\mathrm{Az}}(2 \mathrm{nmi})$.

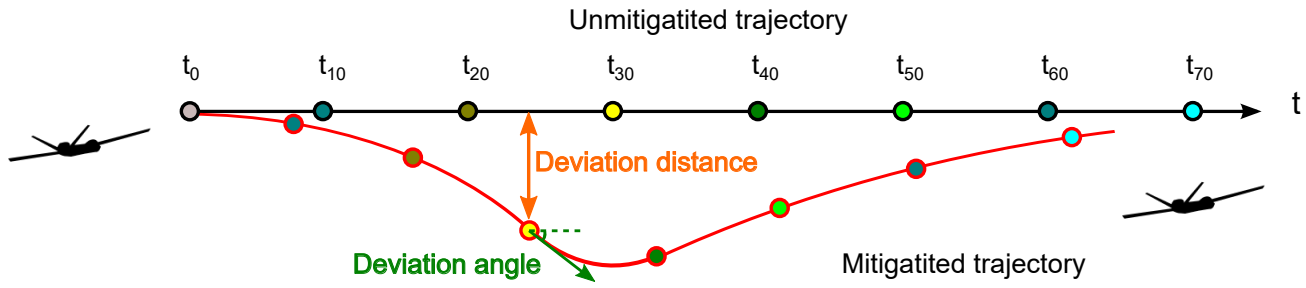

Fig. 11 Trajectory deviation diagram (modified from $[\overline{8}]$ ).

Thus, without considering system delays, four maneuvering options: 4, 6, 7, and 8 in Table 6 (i.e., [0, L2, L1], $[L 2,0, L 1],[L 2, L 1,0]$, and $[L 2, L 1, L 1])$ can be selected for UA to avoid LoWC in the head-on encounter in Fig. 12

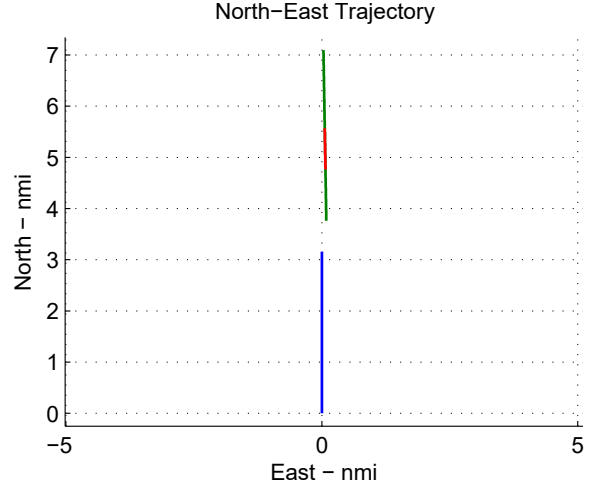

(a) Head-On

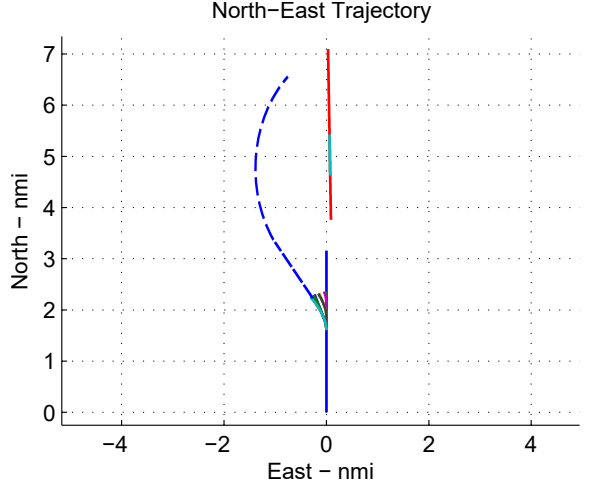

(b) Mitigated Trajectories

Fig. 12 Sample mitigation analysis in a head-on encounter.

Table 6 List of sample analysis results from eight suggested maneuvering options on a three-level decision tree in a head-on encounter.

\begin{tabular}{|c|c|c|c|c|c|c|c|c|c|c|}
\hline \multirow{2}{*}{$\begin{array}{l}\text { Option } \\
\text { index }\end{array}$} & \multirow[t]{2}{*}{$t_{0}$} & \multirow[t]{2}{*}{$t_{0}+10$} & \multirow[t]{2}{*}{$t_{0}+20$} & \multicolumn{4}{|c|}{$\begin{array}{c}\text { Predicted } \\
P_{\text {risk }}(\text { Collision }) \text { with delays }\end{array}$} & \multirow{2}{*}{$\begin{array}{c}\text { Deviation } \\
\text { distance } \\
(\mathrm{nmi})\end{array}$} & \multirow{2}{*}{$\begin{array}{c}\text { Deviation } \\
\text { angle } \\
\text { (deg) }\end{array}$} & \multirow{2}{*}{$\begin{array}{c}\text { Least } \\
\text { disruptive } \\
\text { maneuver }\end{array}$} \\
\hline & & & & $0 \mathrm{sec}$ & $5 \mathrm{sec}$ & $10 \mathrm{sec}$ & $15 \mathrm{sec}$ & & & \\
\hline 1 & 0 & 0 & 0 & 0.73 & 0.76 & 0.78 & 0.79 & 0.00 & 0.00 & \\
\hline 2 & 0 & 0 & L2 & 0.59 & 0.63 & 0.66 & 0.69 & 0.05 & 21.60 & \\
\hline 3 & 0 & L2 & 0 & 0.55 & 0.59 & 0.62 & 0.65 & 0.14 & 21.60 & \\
\hline 4 & 0 & L2 & L1 & 0.43 & 0.48 & 0.52 & 0.56 & 0.16 & 32.69 & \\
\hline 5 & L2 & 0 & 0 & 0.51 & 0.55 & 0.58 & 0.61 & 0.23 & 21.60 & \\
\hline 6 & L2 & 0 & L1 & 0.39 & 0.43 & 0.47 & 0.52 & 0.26 & 32.69 & \\
\hline 7 & L2 & L1 & 0 & 0.37 & 0.41 & 0.45 & 0.49 & 0.29 & 32.69 & $\checkmark$ \\
\hline 8 & L2 & L1 & L1 & 0.24 & 0.29 & 0.35 & 0.40 & 0.31 & 44.10 & \\
\hline
\end{tabular}


Note that the maneuvering option $[0, L 2, L 1]$ suggests that the PIC should command the UA to maintain level flight in $\left[t_{0}, t_{0}+10\right)$, take an $L 2$ turn horizontal maneuver in $\left[t_{0}+10, t_{0}+20\right)$, and perform an $L 1$ turn horizontal maneuver in $\left[t_{0}+20, t_{0}+30\right)$.

\section{Decision Making}

1) For suitable DAA guidance in UAS operations, system delays (i.e., delays from sensor measurements, data communications, pilot decisions, command executions and aerodynamic responses) have to be considered in the decision making [21]. Thus, suggested maneuvering options should be able to handle system delays of 5 to 15 seconds [22]; namely, maneuvering options 4 and 6 in Table 6 are not suitable maneuvering options when system delays of 10 to 15 seconds are introduced in the prediction.

2) For better mitigation performance, the least disruptive maneuver should be chosen when more than one suitable maneuvering option is available on the decision tree. In this case, maneuvering option 7 (i.e., $[L 2, L 1,0]$ ) in Table 6 is selected to guide small UAS self-separation, because of less deviation from the original flight course (in both deviation distance and deviation angle) at the lookahead horizon $\left(t_{0}+30 \mathrm{sec}\right)$ between maneuvering options 7 and 8 in Table 6

3) For the cases when no maneuvering option can meet $P_{\text {risk }}(\text { Collision })_{\text {predicted }}<0.5$ on the six-level decision tree, the maneuvering option with the maximum $H M D_{\text {predicted }}$ should be selected as the suggested DAA guidance.

It is pointed out that the learning-based SDTM is designed to provide the best available DAA supervisory guidance (i.e., maneuvering timing and maneuvering options) in real-time to help small UAS avoid potential LoWCs or NMACs during mid-air encounters, rather than to determine the best solutions from all possible maneuvering options through MC simulations over a long period of time. Moreover, with the further improvement on the policy network constructed for online supervisory guidance, the learning-based SDTM will be able to provide better maneuvering options that are converging to the optimal maneuvering options for small UAS self-separation. 


\section{Encounter Mitigation Performance Analysis}

In this section, to check the mitigation performance of the newly-developed DAA guidance method (the learning-base SDTM), numerous simulated mid-air encounters are performed on a fast-time encouter simulation platforn $\square$ developed by Fang in [2]. With this platform, we can evaluate and analyze the SDTM mitigation performance through a variety of repeatable mid-air encounters, either on specified encounter geometries (e.g., head-on, UA overtaken, UA overtaking, oblique UA overtaking, and converging traffic UA overtaking [8]), or on millions of simulated mitigated and unmitigated encounters among a comprehensive set of encounter geometries [26]. These performance analyses are summarized in a series of case studies and described as follows:

\section{Case study 1: mitigation decisions made by a three-level decision tree}

Fig. 13a shows a pair of horizontal trajectories with a north heading UA and a left-converging traffic in a mid-air encounter, in which the initial conditions are: the detected traffic bearing at $327^{\circ}$ (the northwest), the traffic heading at $125^{\circ}$ (the southeast), the south wind $\left(10^{\circ}\right)$ at $20 \mathrm{kt}$, the UA ground speed at $95 \mathrm{kt}$, and the traffic ground speed at $136 \mathrm{kt}$. In this encounter, the mitigation enabling condition $P_{\text {risk }}($ Collision $) \geq 0.5$ is reached at the horizontal range $r=4.02$ nmi when the predicted $\tau_{m o d}=72 \mathrm{sec}, H M D=0.08 \mathrm{nmi}(486 \mathrm{ft})$ and $V_{s}=609 \mathrm{ft}$. As listed in Table 7 the predicted collision risk levels at $\left(t_{0}+30\right)$ keep changing with various system delays considered in the decision making. Hence, to handle non-removable system delays of 5 to 15 seconds, maneuvering option 5 in Table 7 (i.e., $[R 3,0,0]$, which indicates to take a $2 g$ right turn at the first choice point for 10 seconds) is selected as the least disruptive maneuver (according to the deviation distance and the deviation angle) for the UA to remain WC and achieve the new separation at $\left(t_{0}+30\right)$ with the horizontal range $r=2.07 \mathrm{nmi}, \tau_{\text {mod }}=51 \mathrm{sec}, H M D=0.86 \mathrm{nmi}(5225 \mathrm{ft})$ and $V_{s}=609 \mathrm{ft}$. Later, as shown in Fig. 13b a simple left turn can be used to return the UA back to the original flight course.

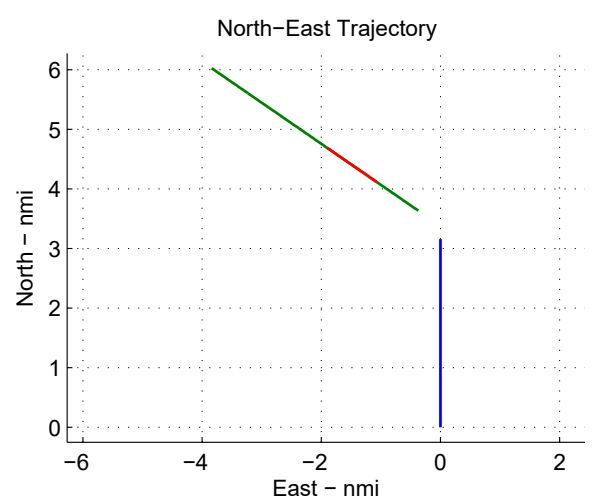

(a) Left-converging Traffic

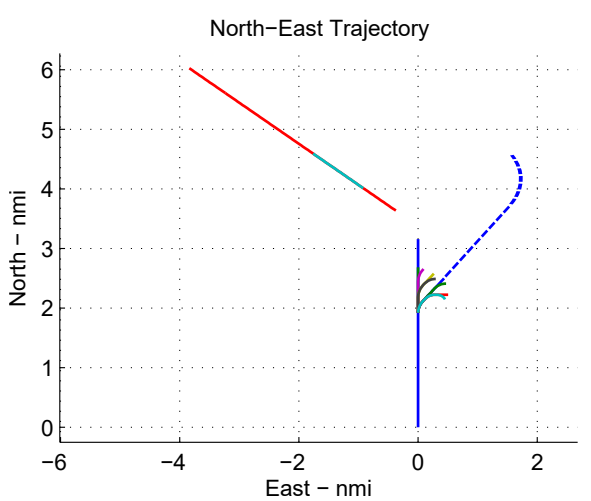

(b) Mitigated Trajectories

Fig. 13 Mitigation performance analysis for a left-converging traffic encounter.

\footnotetext{
"The simulated mid-air encounters on this platform are generated based on the statistical aircraft encounter models developed by the MIT Lincoln Laboratory using Markov predictions on dynamic Bayesian networks over the ground radar data from more than 200 radar systems across the United States [23-25].
} 
Table 7 Maneuvering options for the encounter with left-converging traffic by a three-level decision tree.

\begin{tabular}{|c|c|c|c|c|c|c|c|c|c|c|}
\hline \multirow[t]{2}{*}{$\begin{array}{l}\text { Option } \\
\text { index }\end{array}$} & \multirow[t]{2}{*}{$t_{0}$} & \multirow[t]{2}{*}{$t_{0}+10$} & \multirow[t]{2}{*}{$t_{0}+20$} & \multicolumn{4}{|c|}{$\begin{array}{c}\text { Predicted } \\
P_{\text {risk }}(\text { Collision }) \text { with delays }\end{array}$} & \multirow{2}{*}{$\begin{array}{c}\text { Deviation } \\
\text { distance } \\
(\mathrm{nmi})\end{array}$} & \multirow{2}{*}{$\begin{array}{c}\text { Deviation } \\
\text { angle } \\
\text { (deg) }\end{array}$} & \multirow{2}{*}{$\begin{array}{c}\text { Least } \\
\text { disruptive } \\
\text { maneuver }\end{array}$} \\
\hline & & & & $0 \mathrm{sec}$ & $5 \mathrm{sec}$ & $10 \mathrm{sec}$ & $15 \mathrm{sec}$ & & & \\
\hline 1 & 0 & 0 & 0 & 0.59 & 0.59 & 0.59 & 0.73 & 0.00 & 0.00 & \\
\hline 2 & 0 & 0 & R3 & 0.44 & 0.48 & 0.51 & 0.68 & 0.09 & 43.02 & \\
\hline 3 & 0 & R3 & 0 & 0.39 & 0.43 & 0.46 & 0.56 & 0.26 & 43.02 & \\
\hline 4 & 0 & R3 & $\mathrm{R} 3$ & 0.12 & 0.21 & 0.30 & 0.50 & 0.30 & 90.28 & \\
\hline 5 & R3 & 0 & 0 & 0.22 & 0.37 & 0.41 & 0.45 & 0.44 & 43.02 & $\checkmark$ \\
\hline 6 & R3 & 0 & R3 & 0.05 & 0.14 & 0.22 & 0.37 & 0.47 & 90.28 & \\
\hline 7 & R3 & R3 & 0 & 0.00 & 0.09 & 0.18 & 0.27 & 0.51 & 90.28 & \\
\hline 8 & R3 & R3 & R3 & 0.00 & 0.00 & 0.02 & 0.23 & 0.45 & 149.80 & \\
\hline
\end{tabular}

\section{Case study 2: mitigation decisions made by a six-level decision tree}

Fig. 14a shows a pair of horizontal trajectories with a north heading UA and a left oblique traffic in a UA overtaking encounter, in which the initial conditions are: the detected traffic bearing at $327^{\circ}$ (the northwest), the traffic heading at $61^{\circ}$ (the northeast), the south wind $\left(10^{\circ}\right)$ at $20 \mathrm{kt}$, the UA ground speed at $95 \mathrm{kt}$, and the traffic ground speed at $76 \mathrm{kt}$.

In this encounter, the mitigation enabling condition $P_{\text {risk }}($ Collision $) \geq 0.5$ is reached at the horizontal range $r=2$ nmi when the predicted $\tau_{m o d}=79 \mathrm{sec}, H M D=0.72 \mathrm{nmi}(4375 \mathrm{ft})$ and $V_{s}=401 \mathrm{ft}$. At the beginning, a three-level decision tree is first constructed for the mitigation process with eight maneuvering options listed in Table 8 and their probable maneuvering trajectories drawn in Fig. $14 \mathrm{~b}$ However, as seen in Table 8 , the predicted collision risk levels at $\left(t_{0}+30\right)$ are all greater than 0.5 on this three-level decision tree, so it requires a further six-level decision tree to make a final maneuvering decision for the UA to remain WC in this encounter (e.g., eight new three-level decision trees are constructed under the eight outputted maneuvering options of the top three-level decision tree).

Table 8 Maneuvering options for the left oblique UA overtaking encounter by the top three-level decision tree.

\begin{tabular}{|c|c|c|c|c|c|c|c|c|c|}
\hline \multirow[t]{2}{*}{$\begin{array}{l}\text { Option } \\
\text { index }\end{array}$} & \multirow[t]{2}{*}{$t_{0}$} & \multirow[t]{2}{*}{$t_{0}+10$} & \multirow[t]{2}{*}{$t_{0}+20$} & \multicolumn{4}{|c|}{$\begin{array}{c}\text { Predicted } \\
P_{\text {risk }}(\text { Collision }) \text { with delays }\end{array}$} & \multirow{2}{*}{$\begin{array}{c}\text { Predicted } \\
H M D \\
(\mathrm{nmi})\end{array}$} & \multirow{2}{*}{$\begin{array}{c}\text { Predicted } \\
\text { range } \\
(\mathrm{nmi})\end{array}$} \\
\hline & & & & $0 \mathrm{sec}$ & $5 \mathrm{sec}$ & $10 \mathrm{sec}$ & $15 \mathrm{sec}$ & & \\
\hline 1 & 0 & 0 & 0 & 1.00 & 1.00 & 1.00 & 1.00 & 0.70 & 1.03 \\
\hline 2 & 0 & 0 & R3 & 0.97 & 1.00 & 1.00 & 1.00 & 0.18 & 1.06 \\
\hline 3 & 0 & R3 & 0 & 0.87 & 0.96 & 1.00 & 1.00 & 0.36 & 1.16 \\
\hline 4 & 0 & R3 & R3 & 0.82 & 0.90 & 0.98 & 1.00 & 1.24 & 1.24 \\
\hline 5 & R3 & 0 & 0 & 0.77 & 0.85 & 0.94 & 1.00 & 0.54 & 1.29 \\
\hline 6 & R3 & 0 & R3 & 0.71 & 0.79 & 0.88 & 0.96 & 1.37 & 1.37 \\
\hline 7 & R3 & R3 & 0 & 0.57 & 0.65 & 0.74 & 0.82 & 1.55 & 1.55 \\
\hline 8 & R3 & R3 & R3 & 0.54 & 0.62 & 0.70 & 0.78 & 1.60 & 1.60 \\
\hline
\end{tabular}




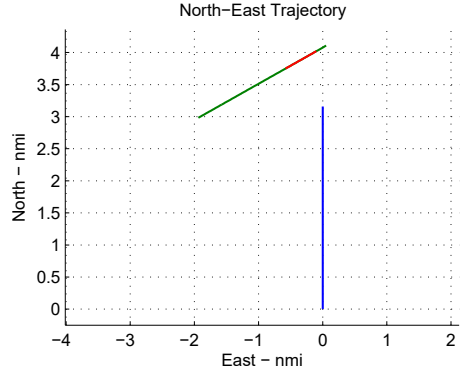

(a) Left oblique UA overtaking

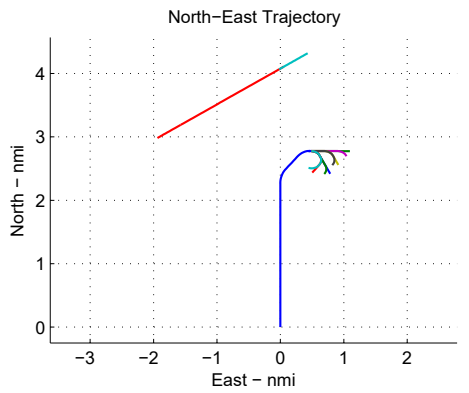

(c) Mitigated trajectories via the six-level decision tree (derived from Option 6 on the top three-level decision tree)

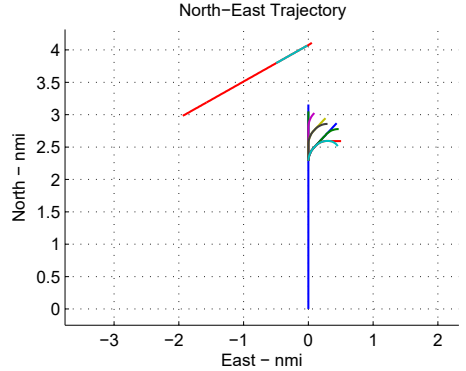

(b) Mitigated trajectories via the three-level decision tree

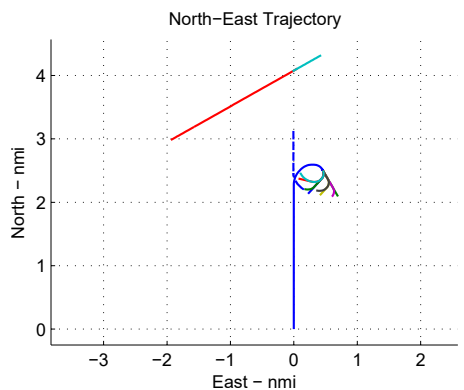

(d) Mitigated trajectories via the six-level decision tree (derived from Option 8 on the top three-level decision tree)

Fig. 14 Mitigation performance analysis for a left oblique UA overtaking encounter.

Table 9 Maneuvering options for the left oblique UA overtaking encounter by the expanded six-level decision tree (for Option 6 and 8 on the top three-level decision tree).

\begin{tabular}{|c|c|c|c|c|c|c|c|c|c|c|}
\hline \multirow{2}{*}{$\begin{array}{l}\text { Option } \\
\text { index }\end{array}$} & \multirow[t]{2}{*}{$t_{0}+30$} & \multirow[t]{2}{*}{$t_{0}+40$} & \multirow[t]{2}{*}{$t_{0}+60$} & \multicolumn{4}{|c|}{$\begin{array}{c}\text { Predicted } \\
P_{\text {risk }}(\text { Collision }) \text { with delays }\end{array}$} & \multirow{2}{*}{$\begin{array}{c}\text { Deviation } \\
\text { distance } \\
(\mathrm{nmi})\end{array}$} & \multirow{2}{*}{$\begin{array}{c}\text { Deviation } \\
\text { angle } \\
\text { (deg) }\end{array}$} & \multirow{2}{*}{$\begin{array}{c}\text { Least } \\
\text { disruptive } \\
\text { maneuver }\end{array}$} \\
\hline & & & & $0 \mathrm{sec}$ & $5 \mathrm{sec}$ & $10 \mathrm{sec}$ & $15 \mathrm{sec}$ & & & \\
\hline$\vdots$ & : & $\vdots$ & $\vdots$ & $\vdots$ & $\vdots$ & $\vdots$ & $\vdots$ & $\vdots$ & & \\
\hline 41 & 0 & 0 & 0 & 0.47 & 0.56 & 0.64 & 0.73 & 1.10 & 90.28 & \\
\hline 42 & 0 & 0 & R3 & 0.44 & 0.53 & 0.61 & 0.70 & 1.04 & 149.80 & \\
\hline 43 & 0 & $\mathrm{R} 3$ & 0 & 0.38 & 0.46 & 0.54 & 0.63 & 0.91 & 149.80 & \\
\hline 44 & 0 & R3 & R3 & 0.39 & 0.47 & 0.55 & 0.64 & 0.82 & 138.19 & \\
\hline 45 & R3 & 0 & 0 & 0.31 & 0.39 & 0.46 & 0.55 & 0.79 & 149.80 & \\
\hline 46 & R3 & 0 & R3 & 0.32 & 0.39 & 0.47 & 0.55 & 0.69 & 138.19 & \\
\hline 47 & R3 & R3 & 0 & 0.36 & 0.43 & 0.50 & 0.58 & 0.50 & 138.19 & \\
\hline 48 & R3 & R3 & R3 & 0.41 & 0.48 & 0.55 & 0.63 & 0.44 & 77.02 & \\
\hline$\vdots$ & $\vdots$ & $\vdots$ & $\vdots$ & $\vdots$ & $\vdots$ & $\vdots$ & $\vdots$ & $\vdots$ & & \\
\hline 57 & 0 & 0 & 0 & 0.08 & 0.16 & 0.23 & 0.31 & 0.70 & 149.80 & \\
\hline 58 & 0 & 0 & $\mathrm{R} 3$ & 0.09 & 0.16 & 0.23 & 0.32 & 0.60 & 138.19 & \\
\hline 59 & 0 & R3 & 0 & 0.12 & 0.19 & 0.26 & 0.34 & 0.41 & 138.19 & \\
\hline 60 & 0 & R3 & R3 & 0.17 & 0.24 & 0.31 & 0.38 & 0.35 & 77.02 & \\
\hline 61 & R3 & 0 & 0 & 0.15 & 0.21 & 0.27 & 0.35 & 0.22 & 138.19 & \\
\hline 62 & R3 & 0 & R3 & 0.19 & 0.26 & 0.32 & 0.39 & 0.17 & 77.02 & $\checkmark$ \\
\hline 63 & R3 & R3 & 0 & 0.32 & 0.38 & 0.43 & 0.51 & 0.07 & 77.02 & \\
\hline 64 & R3 & $\mathrm{R} 3$ & R3 & 0.37 & 0.43 & 0.49 & 0.56 & 0.10 & 77.02 & \\
\hline
\end{tabular}


According to the predictions in Table 9 and in consideration of various system delays in decision making, maneuvering option 62 in Table 9 (derived from maneuvering option 8 in Table 8, namely, [R3, R3, R3, R3, 0, R3]) is selected as the least disruptive maneuvering option from all the qualified maneuvering options (e.g., options 57 - 62) in Table 9 with the predicted collision risk levels at $t_{0}+60$. Note that maneuvering option 60 in Table 9 is another qualified maneuvering option with the deviation angle at $77.02^{\circ}$ but it is not the least disruptive maneuver because of the larger deviation distance $(0.35>0.17 \mathrm{nmi})$. As with the maneuvering trajectories predicted in Fig. $14 \mathrm{~d}$, the UA is almost back to the original flight course when maneuvering option 62 is selected.

\section{Case study 3: mitigation decisions made by various mitigation methods}

In this case study, for performance comparisons, we carry out a series of mitigation performance analyses over five typical encounter geometries as listed in Table 10 and Table 11 using two mitigation methods: the learning-base SDTM developed in Section III and a predefined Collision Avoidance Horizontal-maneuvering Method (CAHM) developed in [2] (in Appendix B). Note that the CAHM was originally designed for collision avoidance but it also can be used for self-separation. In addition, the wind conditions for the encounters listed in Table 10 and Table 11 are $20 \mathrm{kt}$ south winds $\left(10^{\circ}\right)$, and the mitigations are enabled with 15-second delays (i.e., 15 seconds after the mitigation enabling condition $P_{\text {risk }}($ Collision $) \geq 0.5$ is reached during mid-air encounters $)$.

The performance comparisons on the maneuvering options and the trajectory deviations are described and listed in Table 10 and Table 11 with the corresponding diagrams, ${ }^{* *}$ in which UA are heading to the north from the origin $(0,0)$ and traffic are in different geometries.

Table 10 Mitigation performance comparison diagrams

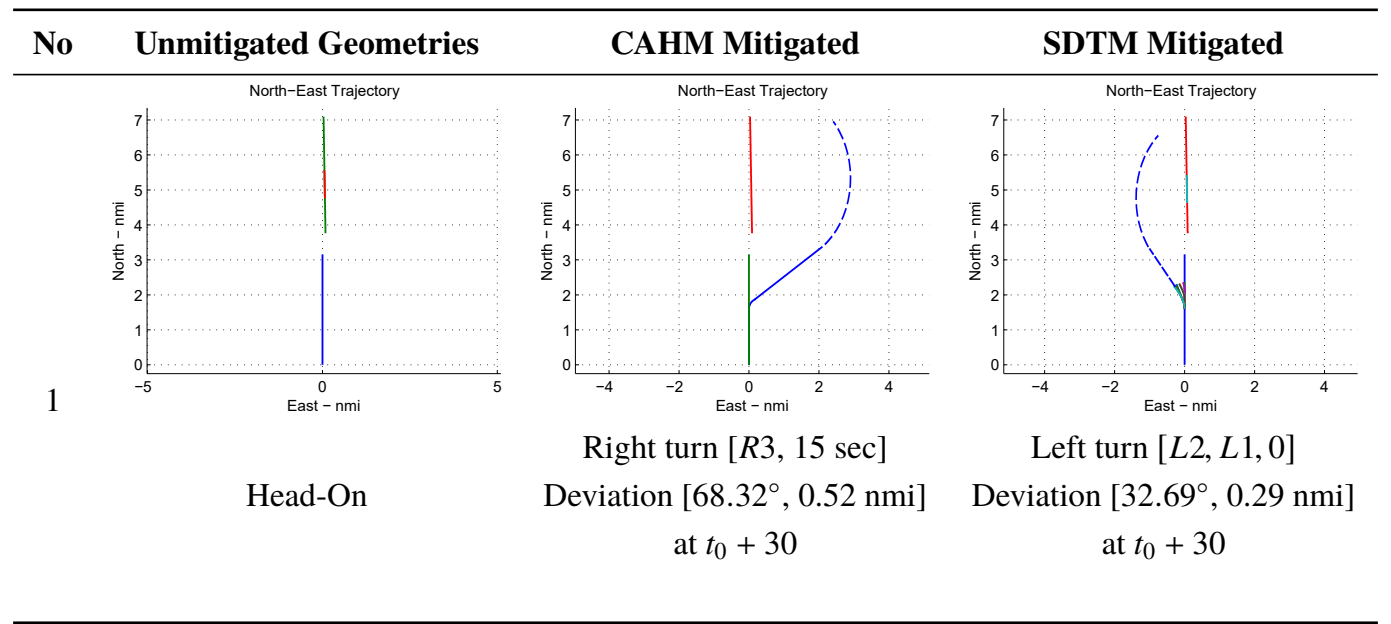

** Note that for encounters on both the left encounter geometries and the corresponding right encounter geometries, the developed severity metrics will give the same triggering results because of encounter symmetries. 
Table 11 Mitigation performance comparison diagrams

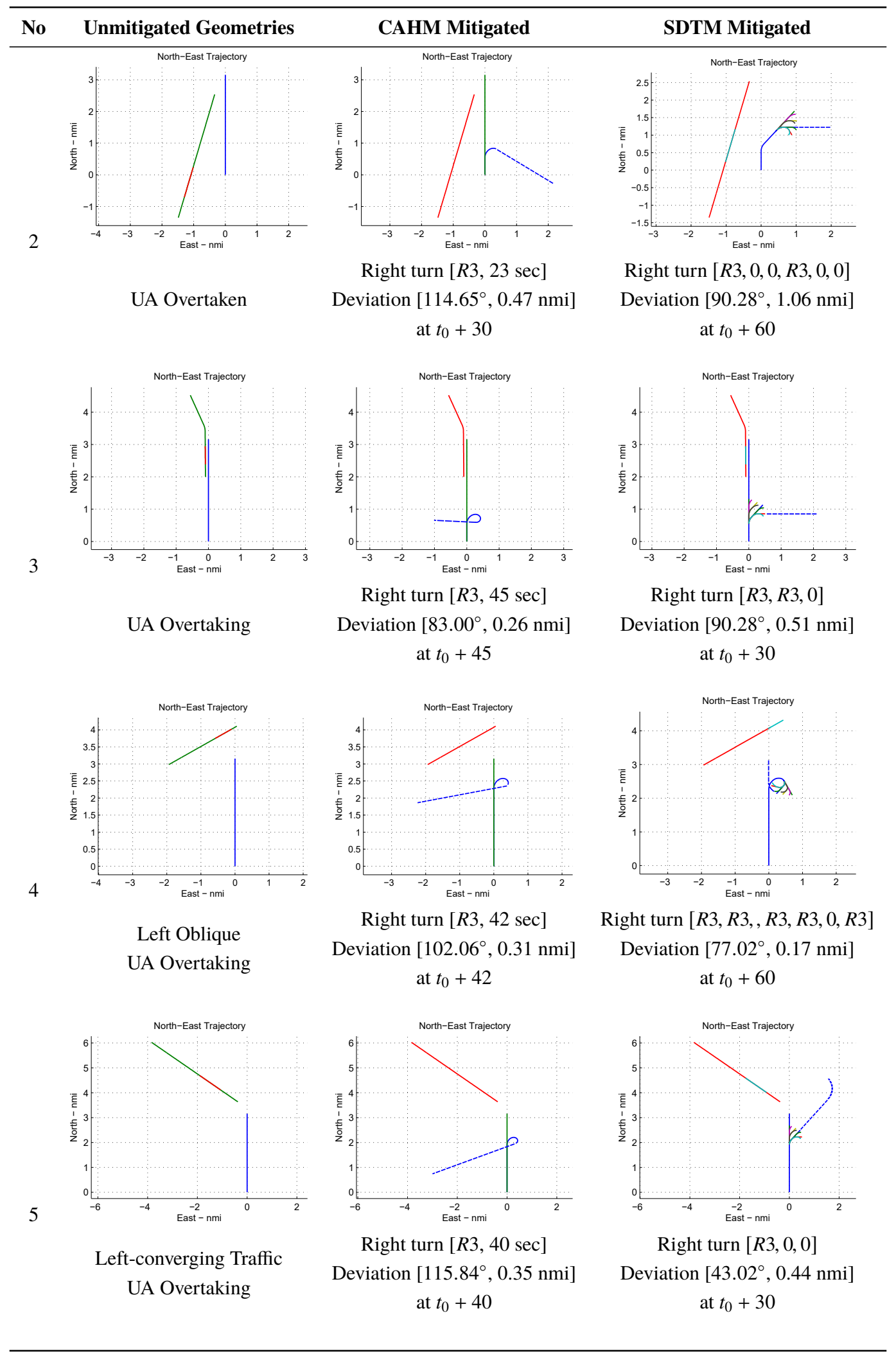


Based on the comparisons in Table 10 and Table 11, we can conclude as follows:

- The SDTM provides less disruptive and more efficient maneuvers for the UA to remain WC: either a lower turn rate during a similar turning time, or less turning time with a similar turn rate. For instance, in the head-on encounter in Table 10, the CAHM initiates a 15-second $2 g$ right turn, and the SDTM triggers two consecutive left turns: a 10 -second $1 g$ left turn followed by another 10 -second $0.5 g$ left turn; namely, the SDTM provides lower turn rates for the UA to remain WC with smaller deviations from the original flight course (with a smaller deviation angle and deviation distance on the simulated maneuvering trajectories).

- The SDTM also intends to select a maneuvering option to help the UA return back to the original flight course easier, e.g., in the left oblique UA overtaking encounter in Table 11, the SDTM provides a maneuvering option with a longer turning time but it guides the UA to almost fly back to the original flight course. After the suggested maneuver is performed for 60 seconds, the traffic is outside of the hazard zone of the UA, so the SDTM can return the UA back to the previous flight immediately.

In addition, as shown in the maneuvering diagrams in Table 10 and Table 11 . multiple suitable maneuvering options are usually available for the PIC to select during UA self-separation. The PIC can pick up them upon the preference of either the safest option or the most efficient option. Therefore, a diagram table like Table 10 or Table 11 can be used as a decision visualization method to guide the PIC to choose appropriate maneuvering decisions in consideration of wind conditions and system delays to avoid LoWCs or NMACs in mid-air encounters.

\section{Case study 4: Risk ratio analysis for mitigation performance evaluation in UAS self-separation}

In this case study, 200 million mid-air encounters in a variety of geometries are generated and analyzed on the fast-time simulation platform for comprehensive risk ratio analysis, in which the wind conditions are set at $20 \mathrm{kt}$ south winds $\left(10^{\circ}\right)$ and the SDTM is employed to provide DAA mitigation guidance during UAS self-separation. In Fig. 15 , three LoWC risk ratios are calculated based on the following risk ratio equations:

$$
\begin{gathered}
\text { RiskRatio }_{\mathrm{ss}}(\text { mitigated })=\frac{P\left(\mathrm{LoWC}_{\text {mitigated }}\right)}{P\left(\mathrm{LoWC}_{\text {unmitigated }}\right)} \\
\text { RiskRatio }_{\mathrm{ss}}(\text { induced })=\frac{P\left(\mathrm{LoWC}_{\text {induced }}\right)}{P\left(\mathrm{LoWC}_{\mathrm{unmitigated}}\right)} \\
\text { RiskRatio }_{\mathrm{ss}}(\text { unresolved })=\frac{P\left(\mathrm{LoWC}_{\mathrm{unresolved}}\right)}{P\left(\mathrm{LoWC}_{\mathrm{unmitigated}}\right)}
\end{gathered}
$$

Where:

$P($ LoWC $\mathrm{mitigated}) \quad$ the probability of the LoWC encounters with mitigation;

$P\left(\right.$ LoWC $\left._{\text {unmitigated }}\right)$ the probability of the LoWC encounters without mitigation; 
$P\left(\right.$ LoWC $\left._{\text {induced }}\right) \quad$ the probability of the newly-induced LoWC encounters with mitigation; and

$P\left(\right.$ LoWC $\left._{\text {unresolved }}\right)$ the probability of the unsolved LoWC encounters with mitigation.

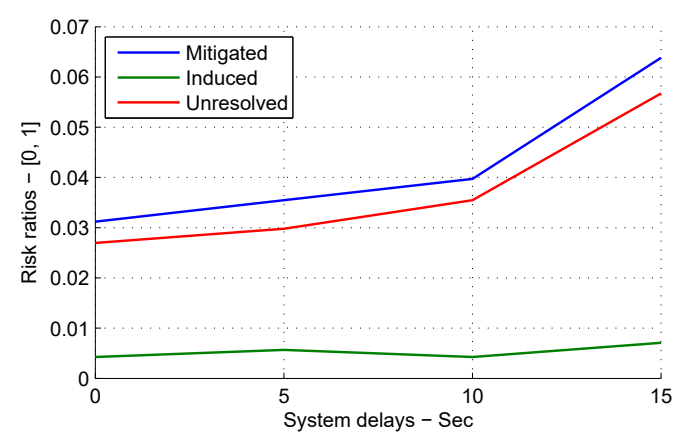

(a) Curve Diagram

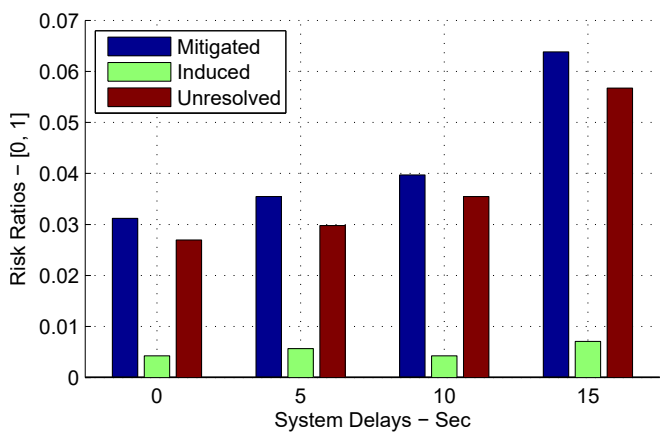

(b) Bar Diagram

Fig. 15 Mitigation performance analysis of LoWC risk ratios in UA self-separation.

The impact of LoWC risk ratios on various system delays (e.g., 0, 5, 10, 15 seconds) are studied in the analytical statistics. For example, in Fig. [15] the mitigated LoWC risk ratios stay at $[0.03,0.04]$ when system delays are within $[0$, 10] seconds, whereas they are almost doubled when system delays are more than 15 seconds. As the induced LoWC risk ratios are always close to constant in Fig. 15, the big increases of mitigated LoWC risk ratios come from the large amount of unresolved LoWCs during mid-air encounters. In other words, the more system delays in the mitigation process the more unresolved LoWCs during mid-air encounters; or, the fewer system delays the better mitigation performance in UAS self-separation. As a result, a mitigation supervisory guidance system like the SDTM becomes essential for the PIC to reduce the decision-making time involving in choosing suitable mitigation solutions to avoid LoWCs or NMACs during UAS self-separation.

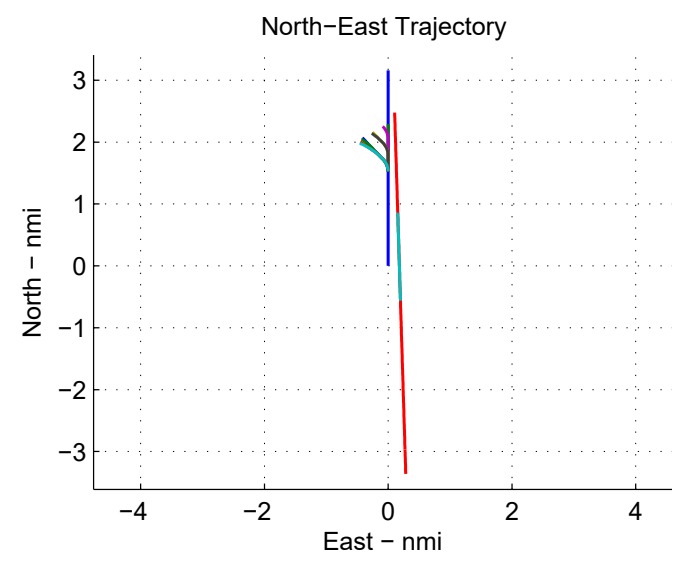

(a) UA Overtaken

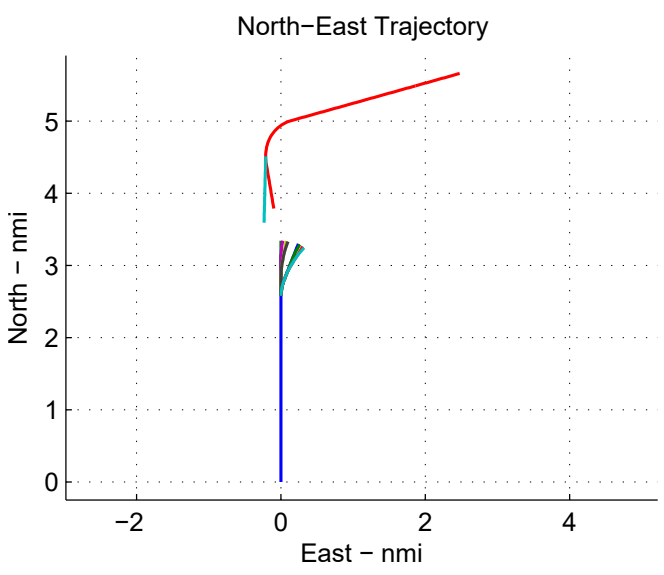

(b) Front-converging Traffic

Fig. 16 Sample diagrams for unresolved LoWC encounters in risk ratio analysis due to system delays. 
In addition, the newly-induced and unresolved LoWC encounters are saved in the database for further investigation and analysis to improve the mitigation performance of DAA systems. For example, in the UA overtaken encounter drawn in Fig. 16a, the UA and traffic fly to the north at $75 \mathrm{kt}$ and $175 \mathrm{kt}$, respectively. The self-separation mitigation is triggered when the collision risk level $P_{\text {risk }}\left(\right.$ Collision) is greater than 0.5 (i.e., $r=2 \mathrm{nmi}, H M D=0.11 \mathrm{nmi}, V_{s}=335$ $\mathrm{ft}$, and $\left.\tau_{\text {mod }}=81 \mathrm{sec}\right)$. As shown in the projection, the UA will be in LoWC in $46 \mathrm{sec}$; however, in consideration of system delays, the UA may not be able to fly to the west far enough to prevent LoWC even with a steep left turn (e.g., $H M D_{t_{0}+46}=0.62 \mathrm{nmi}$, which is still within the minimum LoWC boundary, $D M O D_{\text {wc }}$ at $4000 \mathrm{ft}$ or $\left.0.66 \mathrm{nmi}\right)$.

Fig. $16 \mathrm{~b}$ shows another unresolved LoWC encounter, where the right-converging traffic has a sudden left turn and heads to the UA. In this encounter, the collision risk level $P_{\text {risk }}($ Collision) is changed from 0 to 0.9 in 20 sec during the traffic's sudden left turn. Meanwhile, $H M D$ is also changed from $2.02 \mathrm{nmi}$ to $0.03 \mathrm{nmi}$ and $\tau_{m o d}$ is changed from 78 sec to $40 \mathrm{sec}$. Thus, the UA bounds to LoWC in terms of the late alerting time involving instinctive system delays.

\section{Conclusion and Future Work}

In this paper, two knowledge-based statistical networks, the policy network and the value network, are first introduced to guide the online decision making and quantitatively evaluate the collision risks during mid-air encounters. With these two networks, the learning-based SDTM is then designed and developed to help small UAS DAA systems choose the optimized mitigation solutions in real-time for UAS self-separation. In addition, to evaluate and qualify the SDTM mitigation performance, millions of simulated mid-air encounters are performed and analyzed on the fast-time simulation platform. The analytical results show that the newly-developed SDTM can be employed to determine the maneuvering timing and choices (with system delays considered) for UAS self-separation to avoid potential LoWCs during mid-air encounters. Future work to generate more precise policy network for small UAS will require further MC simulations covering more wind conditions (more wind speeds and wind directions), and more velocities for both UA and mid-air traffic. Later, planned future work will also include to implement this learning-based SDTM to a DAA system for small UAS flight tests on the hardware-in-loop simulator and in the field.

\section{Appendix A: Fernandez-Guasti (FG) Norm Operation}

For risk synthesis to combine three normalized penetration components of collision risk levels, the FG squircle operators $(\oplus)$ in Eq. 17 refer to FG Norm operations and can be mathematically defined as [8]

$$
a \oplus b=\sqrt{a^{2}+\left(1-a^{2}\right) b^{2}}
$$

As depicted in Fig. 17, the FG Norm operation is better than the multiplication operation $(a \times b)$, which always moves toward low values; and it also is better than the maximum operation $\max (a, b)$, which does not show variations 


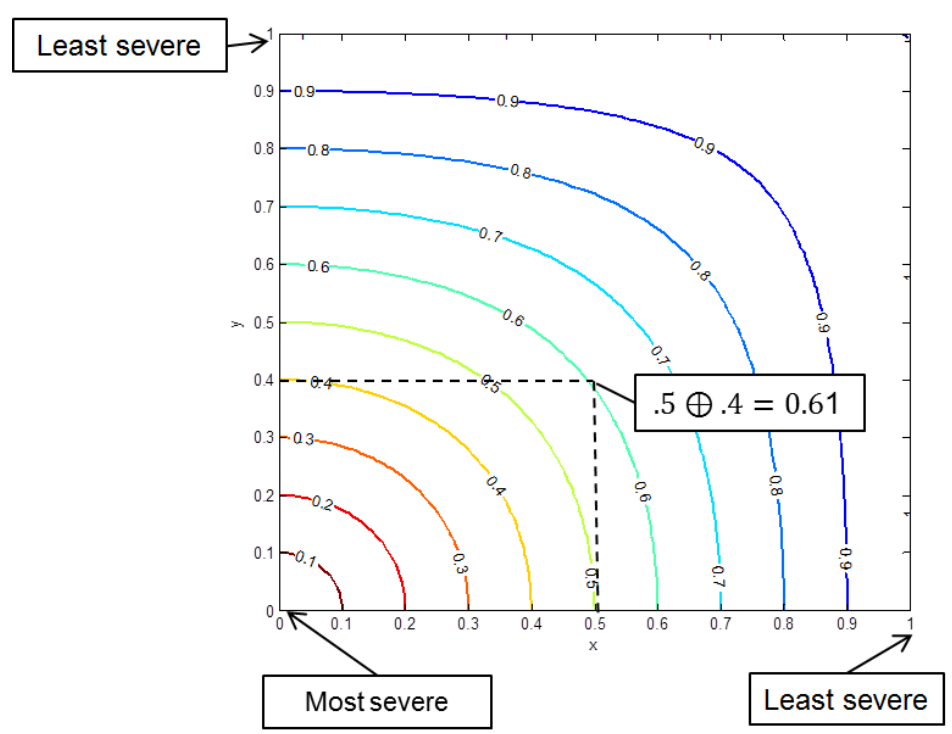

Fig. 17 A sample FG Norm operation diagram [8].

in the lesser component [27]. The FG Norm operation in Eq. 26 was originally designed to combine two normalized components ranging from 1 (least severe) to 0 (most severe) [27]. To combine three normalized components in Eq. 17 , FG Norm operations should meet the following necessary properties [8, 27]:

- $a \oplus b=b \oplus a$ (commutative)

- $a \oplus(b \oplus c)=(a \oplus b) \oplus c$ (associative)

- $1 \oplus a=1$ for any $a$

- $0 \oplus a=a$ for any $a$

- $0 \oplus a=0$ if and only if $a=0$.

\section{Appendix B: Collision Avoidance Maneuvering Algorithm}

When small UAS self-separation fails (i.e., when traffic aircraft are approaching the WC boundary in the hazard zone and NMACs are projected), small UAS should exit from self-separation mitigation and enter collision avoidance mitigation to avoid coming NMACs. To help small UAS handle such emergencies immediately, we develop a predefined three-dimensional evasive maneuvering algorithm, which consists of two components: horizontal maneuvering strategy and vertical maneuvering strategy.

\section{A. Horizontal maneuvering strategy in the three-dimensional evasive maneuvering algorithm}

In Fig. 18, once NMACs are projected and the break-ins are predicted on the WC boundary in the next five seconds, the evasive maneuvering algorithm evaluates collision risks and triggers horizontal maneuvers, based on the 


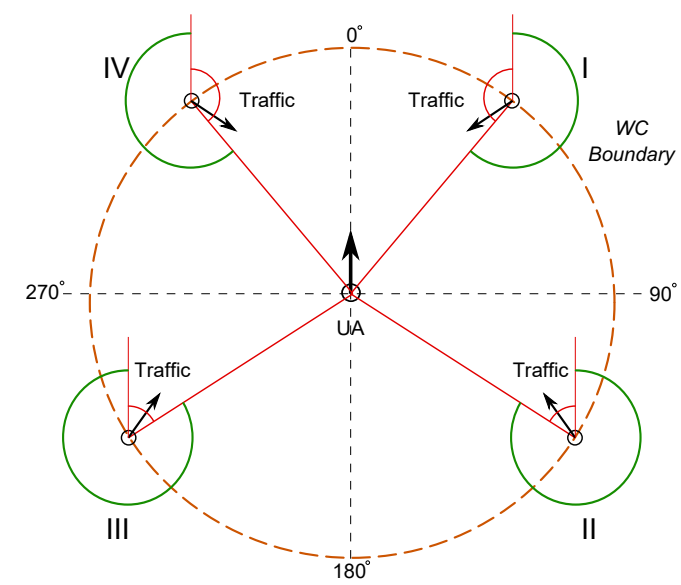

Fig. 18 Horizontal maneuvering strategies in the three-dimensional evasive maneuvering algorithm.

traffic-detected relative bearing $\left(\beta_{\text {твағнсі }}\right)$ and the traffic relative heading $\left(\psi_{\text {твағғс }}\right)$ with respect to the UA in four quadrants from $0^{\circ}$ to $360^{\circ}$. In each quadrant in Fig. 18 , when traffic are heading to the red regions (displayed as the red arc areas), the algorithm starts to initiate evasive maneuvers to steer the UA to the safe regions which are far away from traffic potential heading areas and stay there until the horizontal range rate $\dot{r}>0$ and the horizontal range $r>D M O D_{A z}(2$ nmi) between the UA and traffic. Assume that maximum $2 g$ turns (turn rate at $6 \% \mathrm{sec}$ ) can be achieved on the UA. The UA horizontal maneuvering options at four quadrants in Fig. 18 are designed differently and their details are described as follows:

\section{Evasive maneuvers in quadrant I}

As shown in Figs. 19a and 19b the maneuvering strategy in quadrant $I$ is to let the UA fly to safe waypoints in quadrant II, which are located at a position $90^{\circ}$ off the traffic break-in bearings on the WC boundary in quadrant II. Upon the traffic break-in bearings, the UA make left turns or right turns to fly to the predefined safe waypoints. The UA make right turns when the break-in bearing is less than $45^{\circ}$; and the UA make left turns when the break-in bearing is greater than $45^{\circ}$.

\section{Evasive maneuvers in quadrant II and III}

In Figs. 19c and 19d two maneuvering strategies are described for the cases when traffic are coming from the rear of the UA. In Fig. 19c, the UA make left turns to fly to the predefined safe waypoints in quadrant III when the traffic break-in bearing is in quadrant II (rear right of the UA). In Fig. 19d, the UA make right turns to fly to the predefined safe waypoints in quadrant II when the traffic break-in bearing is in quadrant III (rear left of the UA). 


\section{Evasive maneuvers in quadrant IV.}

In Figs. 19e and 19f the UA make left turns to fly to the predefined safe waypoints in quadrant III when the break-in bearing is greater than $315^{\circ}$; and the UA make right turns to fly to the predefined safe waypoints in quadrant III when the break-in bearing is less than $315^{\circ}$.

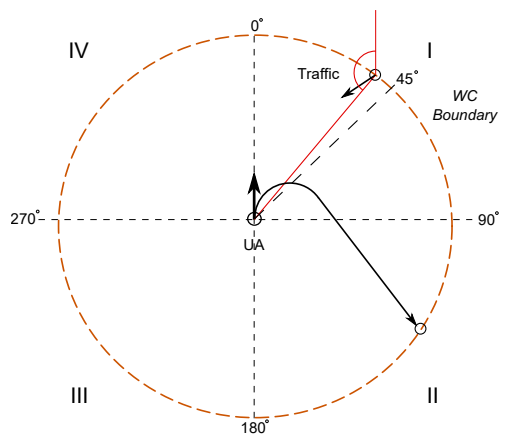

(a) Break-in bearing $<45^{\circ}$ in quadrant I

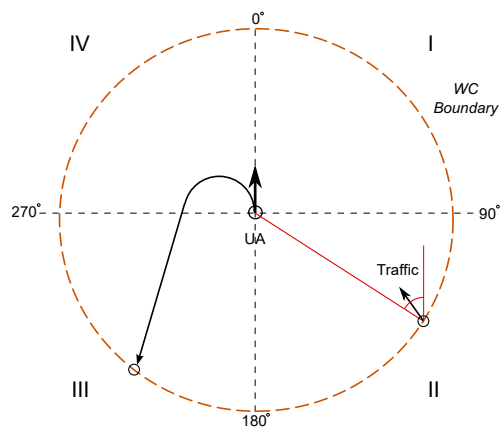

(c) Break-in bearing locations in quadrant II

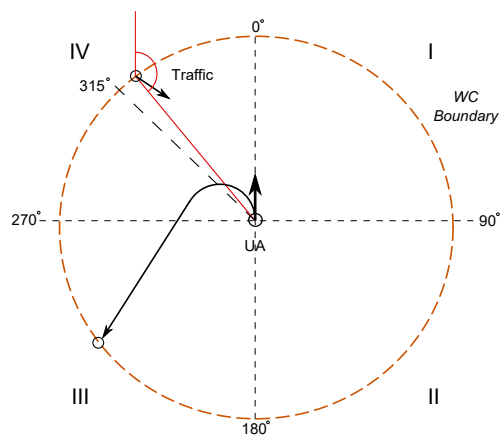

(e) Break-in bearing $>315^{\circ}$ in quadrant IV

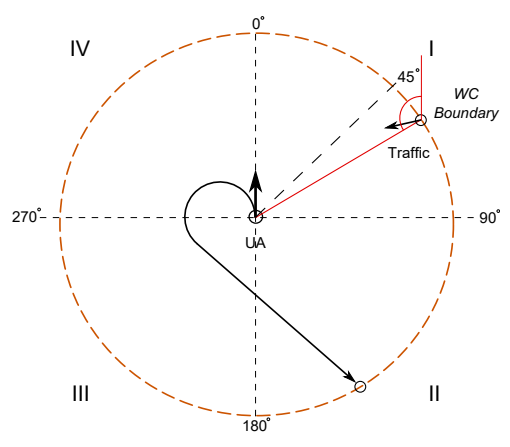

(b) Break-in bearing $>45^{\circ}$ in quadrant I

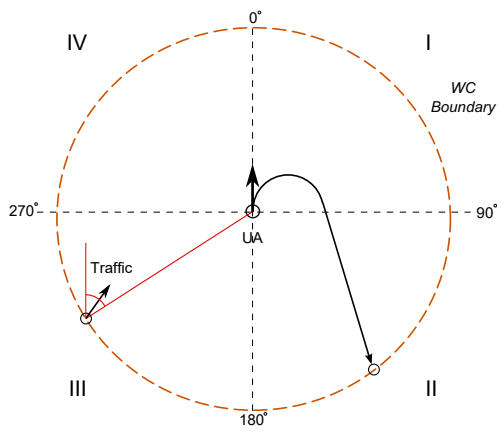

(d) Break-in bearing locations in quadrant III

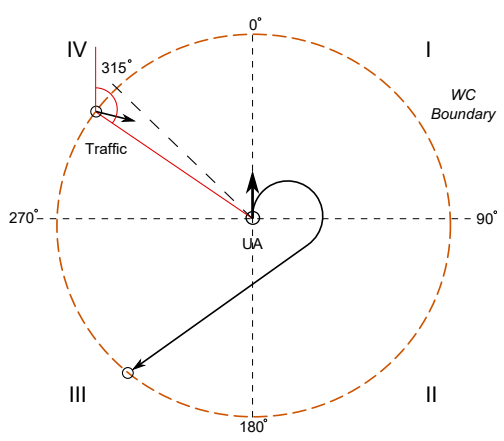

(f) Break-in bearing $<315^{\circ}$ in quadrant IV

Fig. 19 Evasive maneuvering strategies in quadrant I, II, III, and IV. 


\section{B. Vertical maneuvering strategy in the three-dimensional evasive maneuvering algorithm}

In collision avoidance mitigation, horizontal and vertical maneuvers are engaged at the same time to help small UAS escape from emergencies as soon as possible. The vertical maneuvering strategy is designed based on the vertical separation $d_{h}$ and the traffic vertical rate $\dot{h}_{\text {твағгі }}$; namely, it is to increase the vertical separation between the UA and traffic, so that the vertical separation at the horizontal CPA can be greater than $100 \mathrm{ft}\left(h_{\text {мммс }}= \pm 100 \mathrm{ft}\right)$. This strategy is described in further detail with the corresponding diagrams for different encounter geometries in Table 12 .

\section{Table 12 Vertical maneuvering strategy}

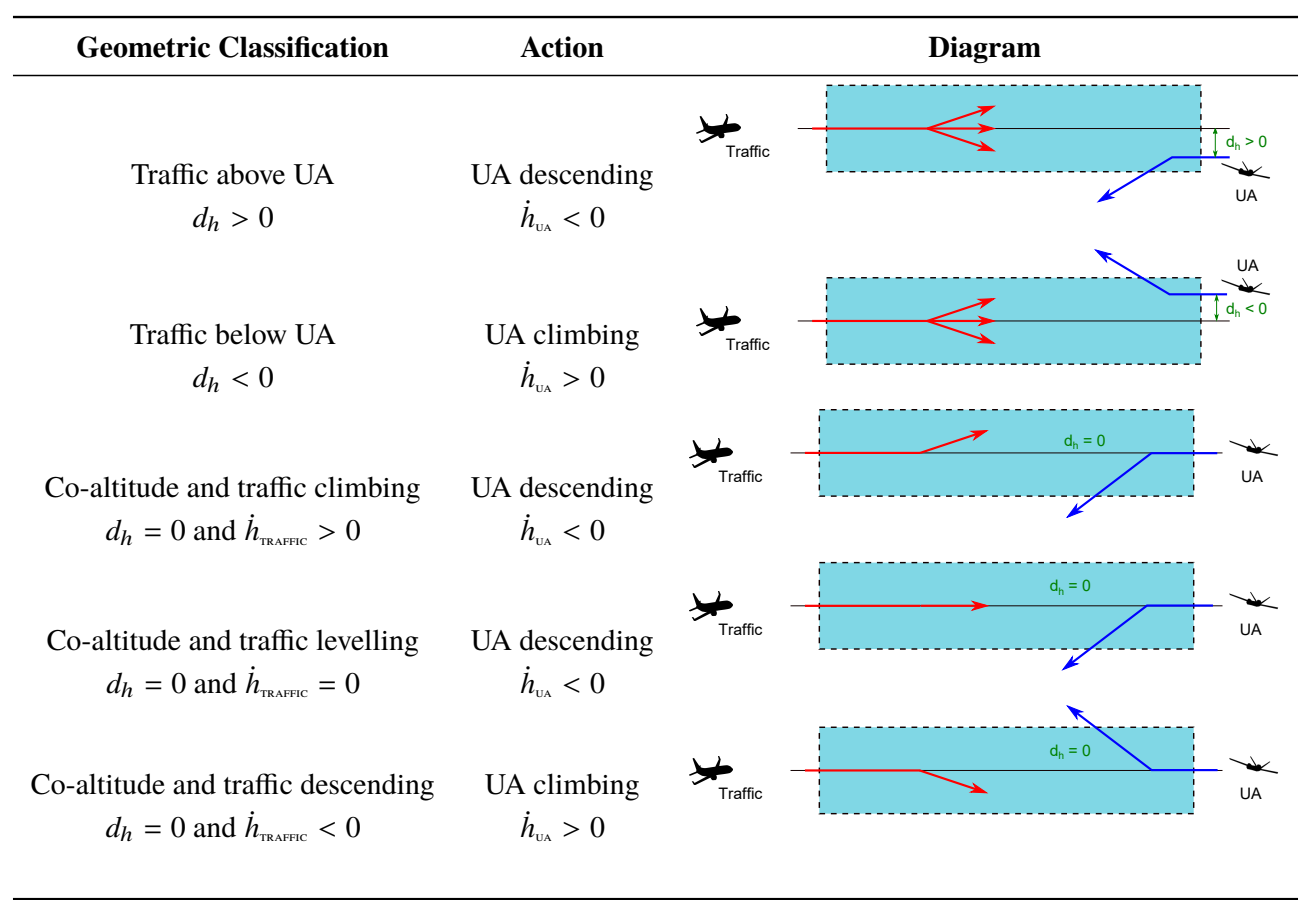

\section{Acknowledgements}

The authors gratefully acknowledge Dilan Amarasinghe, Jon Stevenson, Bruno Miranda Artacho and the RAVEN team for help and guidance in this research.

\section{References}

[1] Fasano, G., Accado, D., Moccia, A., and Moroney, D., "Sense and avoid for unmanned aircraft systems," IEEE Aerospace and Electronic Systems Magazine, Vol. 31, No. 11, 2016, pp. 82-110. doi:10.1109/maes.2016.160116.

[2] Fang, S. X., "Risk-based Supervisory Guidance for Detect and Avoid involving Small Unmanned Aircraft Systems," phdthesis, Memorial University, St. John's, NL, Canada, 2017.

[3] Kuchar, J. K., and Yang, L. C., "A review of conflict detection and resolution modeling methods," IEEE Transactions on Intelligent Transportation Systems, Vol. 1, No. 4, 2000, pp. 179-189. doi:10.1109/6979.898217. 
[4] Albaker, B. M., and Rahim, N. A., "A survey of collision avoidance approaches for unmanned aerial vehicles," 2009 International Conference for Technical Postgraduates (TECHPOS), 2009, pp. 1-7. doi:10.1109/TECHPOS.2009.5412074.

[5] Carpenter, B. D., and Kuchar, J. K., "A Probability-Base Alerting Logic for Aircraft on Parallel Approach,” techreport, Massachusetts Inst. of Tech.; Cambridge, MA United States, Apr. 1997. NASA-CR-201685.

[6] Sun, L., Hedengren, J. D., and Beard, R. W., "Optimal Trajectory Generation Using Model Predictive Control for Aerially Towed Cable Systems," Journal of Guidance, Control, and Dynamics, Vol. 37, No. 2, 2014, pp. 525-539. doi:10.2514/1.60820, URL https://doi .org/10.2514/1.60820

[7] Radio Technical Commission for Aeronautics (RTCA), "Minimum Operational Performance Standards for Traffic Alert and Collision avoidance System II (TCAS II),” Document No: RTCA/DO-185B, Washington, DC, RTCA, Inc., Jun. 2008.

[8] Radio Technical Commission for Aeronautics (RTCA), "Minimum Operational Performance Standards (MOPS) for Detect and Avoid (DAA) Systems,” Document No: RTCA/DO-365, Washington, DC, RTCA, Inc., 2017.

[9] Gibney, E., “Google AI algorithm masters ancient game of Go,” Nature, Vol. 529, 2016, pp. 445-446. doi:doi:10.1038/529445a, URL https://ai.arizona.edu/sites/ai/files/resources/gibney_2016_google_masters_go.pdf

[10] Silver, D., Huang, A., Maddison, C. J., Guez, A., Sifre, L., van den Driessche, G., Schrittwieser, J., Antonoglou, I., Panneershelvam, V., Lanctot, M., Dieleman, S., Grewe, D., Nham, J., Kalchbrenner, N., Sutskever, I., Lillicrap, T., Leach, M., Kavukcuoglu, K., Graepel, T., and Hassabis, D., "Mastering the game of Go with deep neural networks and tree search,” Nature, Vol. 529, No. 7587, 2016, pp. 484-489. doi:doi:10.1038/nature16961, URL http://dx.doi.org/10.1038/nature16961

[11] Hull, D. G., Fundamentals of Airplane Flight Mechanics, Springer-Verlag Berlin Heidelberg, 2007. doi:10.1007/978-3-54046573-7.

[12] Lee, S. M., Park, C., Johnson, M. A., and Mueller, E. R., "Investigating Effects of Well Clear Definitions on UAS Sense-AndAvoid Operations in Enroute and Transition Airspace," 2013 Aviation Technology, Integration, and Operations Conference, AIAA AVIATION Forum, American Institute of Aeronautics and Astronautics, 2013. doi:10.2514/6.2013-4308, URL http://dx.doi.org/10.2514/6.2013-4308

[13] Radio Technical Commission for Aeronautics (RTCA), "Minimum Operational Performance Standards (MOPS) for Traffic Alert and Collision Avoidance System II (TCAS II) Hybrid Surveillance,” Document No: RTCA/DO-300, Washington, DC, RTCA, Inc., 2006.

[14] Sunday, D., "Distance between 3D Lines \& Segments," From softSurfer, Oct. 2017. URL http://geomalgorithms . com/a07_distance.html

[15] Johnson, M., Mueller, E. R., and Santiago, C., "Characteristics of a Well Clear Definition and Alerting Criteria for Encounters between UAS and Manned Aircraft in Class E Airspace,” Eleventh USA/Europe Air Traffic Management Research and Development Seminar (ATM2015), 2015. URL http://wWW. atmseminar .org/seminarContent/seminar11/papers/ 388-Johnson_0123150804-Final-Paper-5-6-15.pdf 
[16] Cook, S. P., Brooks, D., Cole, R., Hackenberg, D., and Raska, V., "Defining Well Clear for Unmanned Aircraft Systems," AIAA Infotech @ Aerospace, AIAA SciTech Forum, American Institute of Aeronautics and Astronautics, 2015. 10.2514/6.2015-0481, URL https://doi.org/10.2514/6.2015-0481

[17] Transport Canada (TC), "Staff Instruction,” Document No: SI 623-001, May 2017. URL https://wWW.tc.gc.ca/eng/ civilaviation/standards/general-recavi-uav-4161.html

[18] McGovern, S. M., Cohen, S. B., Truong, M., and Fairley, G., "Kinematics-based model for stochastic simulation of aircraft operating in the national airspace system," 2007 IEEE/AIAA 26th Digital Avionics Systems Conference, 2007, pp. 3.B.2-1-3.B.2-11. doi:10.1109/DASC.2007.4391876.

[19] HWACI, “About SQLite,” Hipp, Wyrick \& Company, Inc., Oct. 2017. URLhttps://www.sqlite.org/about.html.

[20] Millan, J. P., “Online Discrete Event Control of Hybrid Systems,” phdthesis, Memorial University of Newfoundland, Oct. 2006.

[21] Kuffner, M. P., Guendel, R., and Darrah, S., "Investigating Traffic Avoidance Maneuver Preferences of Unmanned Aircraft Operators," 16th AIAA Aviation Technology, Integration, and Operations Conference, AIAA AVIATION Forum, American Institute of Aeronautics and Astronautics, 2016. doi:10.2514/6.2016-3289, URLhttps://doi .org/10.2514/6.2016-3289

[22] Baillie, S., Crowe, W., Edwards, E., and Ellis, K., "Small RPAS Best Practices for BVLOS," , Oct. 2016. URL https: //www.unmannedsystems.ca/download-usc-small-rpas-best-practices-document/.

[23] Kochenderfer, M. J., Kuchar, J. K., Espindle, L. P., and Griffith, J. D., "Uncorrelated Encounter Model of the National Airspace System," Project Report ATC-345, Massachusetts Institute of Technology, Lincoln Laboratory, 2008. URL http://www.1l.mit.edu/mission/aviation/publications/publication-files/atc-reports/ Kochenderfer_2008_ATC-345_WW-18178.pdf.

[24] Kochenderfer, M. J., Espindle, L. P., Kuchar, J. K., and Griffith, J. D., "Correlated Encounter Model for Cooperative Aircraft in the National Airspace System," Project Report ATC-344, Massachusetts Institute of Technology, Lincoln Laboratory, 2008. URL http://www.1l.mit.edu/mission/aviation/publications/publication-files/atcreports/Kochenderfer_2008_ATC-344_WW-18099.pdf

[25] Weinert, A. J., Harkleroad, E. P., Griffith, J. D., Edwards, M. W., and Kochenderfer, M. J., "Uncorrelated Encounter Model of the National Airspace System Version 2.0," Project Report ATC-404, Massachusetts Institute of Technology, Lincoln Laboratory, 2013. URL http://www.dtic.mil/cgi-bin/GetTRDoc?AD=ADA589697

[26] Zeitlin, A., Sense and Avoid in UAS: Chapter 2 Performance Tradeoffs and the Development of Standards, John Wiley \& Sons, Ltd, 2012, Chap. 2, pp. 35-54. doi:10.1002/9781119964049.ch2, URL http://dx.doi .org/10.1002/9781119964049.ch2

[27] Kay, J., and Pratt, E., “Severity of Loss of Well Clear,” RTCA Workspace, Mar. 2016. 